\title{
Geochemical Dynamics of the Natural-Gas Hydrate System in the Sea of Marmara, Offshore Turkey
}

\author{
Livio Ruffine et al.* \\ IFREMER, Centre de Brest, \\ Département des Géosciences Marines, Plouzané,
}

France

\section{Introduction}

Natural-gas hydrate systems are solid-state light-hydrocarbon accumulations which are encountered in the permafrost and the continental margins. They are stable under highpressure and low-temperature conditions and represent the major hydrocarbon volume on earth (Kvenvolden, 1988). Gas hydrates consist of a polycrystalline structure where a light hydrocarbon is trapped within a water lattice. The nature of the hydrocarbons is strongly related to their origin which is either microbial (also called biogenic) or thermogenic. Microbial gas-hydrate systems contain hydrocarbons produced by bacteria and archaea. There are primarily methane with a very small amount of ethane and eventually propane (Max, 2003). Others non-hydrocarbon compounds like hydrogen sulphur and carbon dioxide are also present. In the case of microbial gases, the hydrates are formed at or near the gas production area. Owing to the very high-methane content, these hydrates are commonly called methane-hydrate systems.

Beside the microbial gas-hydrate systems, there are hydrate accumulations which are connected to a petroleum system (Max, 2003). Thus, the hydrate-forming gases have a thermogenic origin. They come from deep subsurface reservoirs of hydrocarbons, may contain hydrocarbons from methane to $\mathrm{C}_{6+}$, and migrate to the shallow sediment where the pressure and the temperature are favourable for hydrate nucleation and growth. Heavier hydrocarbons like isobutane, isopentane, neopentane can be trapped into the water lattice.

\footnotetext{
* Olivia Fandino ${ }^{1}$, Joël Etoubleau ${ }^{1}$, Sandrine Chéron ${ }^{1}$, Jean-Pierre Donval ${ }^{1}$, Yoan Germain ${ }^{1}$, Emmanuel Ponzevera ${ }^{1}$, Vivien Guyader ${ }^{1}$, Bernard Dennielou${ }^{1}$, Giuseppe Etiope ${ }^{2}$, Luca Gasperini ${ }^{3}$, Bortoluzzi Giovanni ${ }^{3}$, Pierre Henry ${ }^{5}$, Céline Grall ${ }^{1,5}$, Çagatay M. Namik ${ }^{6}$, Charlou Jean-Luc ${ }^{1}$ and Géli Louis ${ }^{1}$ ${ }_{1}^{1}$ IFREMER, Centre de Brest, Département de Géosciences Marines, Plouzané, France

2Istituto Nazionale di Geofisica e Vulcanologia, Sezione Roma, Roma, Italy

${ }^{3}$ Université Europeenne Bretagne, UBO IUEM, Plouzane, France

${ }^{4} I S M A R, C N R$, Bologna, Italy

${ }^{5}$ Aix-Marseille Univ., CEREGE, France

${ }^{6}$ Istanbul Technical University, Istanbul, Turkey
} 
Since the beginning, investigations on natural-gas hydrates connected to or in relation with a petroleum system have held a prominent position in geosciences as they have been considered as a geohazard for the petroleum industry (Kvenvolden, 1999; Kvenvolden, 2000; Sloan and Koh, 2008). Now natural-gas hydrate systems are seen as a potential energy resource, and investigations are shifting mainly towards the study of the gashydrate production. This corresponds to a second period in the young history of naturalgas hydrate systems. However, the production of all hydrate accumulations is not economically viable and the scientific insights gained up to now from studies of gas hydrates as a geohazard is of immense value for the understanding of the behaviour of such complex systems. Therefore, applied research on gas hydrates will still be focused on both fields of interest. Beside, the industrial interests, there is a debate on the destabilisation of natural-gas hydrate systems and their contribution to climate change (Henriet and Mienert, 1998; Krey et al., 2009; Maslin et al., 2010; Yamamoto et al., 2009). In fact, if this huge amount of methane bound into the hydrates is released and reach the atmosphere, it would certainly impact on the climate by raising the temperature as methane is a greenhouse gas. However, there is an ongoing scientific debate about the likelihood for important quantity of methane being released from oceanic hydrates to reach the atmosphere (Reagan and Moridis, 2008).

Whatever the scientific and industrial purposes, the study of natural-gas hydrate systems now involves more and more multidisciplinary approach. Fortunately, thanks to the everincreasing deep-sea technology development, scientists are able to recover well-preserved samples from different types of geological setting, perform several kinds of analysis and obtain more accurate measurements. More specifically, development of seismic techniques also allows a better visualisation of hidden structures underneath the hydrate accumulations (Collett et al., 2010; Paull and Dillon, 2001; Plaza-Faverola et al., 2010). The resulting data of all those techniques and analyses are gathered, integrated and combined to advance our understanding on natural-gas hydrate systems.

Geochemistry plays an important role in the understanding of a natural-gas hydrate system (Paull and Dillon, 2001). It allows the chemical identification of the different materials involved in the hydrate formation as well as the determination of their origin. Such information enables us to constrain the hydrate formation, accumulation and destabilisation processes, and therefore geochemistry contributes to a large part in the description of the system's dynamics. This chapter is dedicated to the application of a series of geochemical analyses to describe a natural-gas hydrate system located on the Western High, in the Sea of Marmara, offshore Turkey. It has been discovered during the Marnaut scientific expedition in 2007 on the R/V L'Atalante. The collected hydrate samples were porous and had a strong smell of oil. The sediment associated with the hydrates was also stained with oil, which strongly suggests a possible link with a petroleum system, possibly with the Thrace basin. Since this expedition in 2007, two others ones dealing with the study of this hydrate system, Marmesonet in 2009 and MARMARA 2010 in 2010, were undertaken. Here, we gather the data from literature, mainly from Bourry's article (Bourry et al., 2009), along with newly generated ones to provide a description of the geochemical dynamics of the Sea of Marmara natural-gas hydrate system. 


\section{Geological setting}

The Sea of Marmara is a $210 \mathrm{~km}$ long and $75 \mathrm{~km}$ wide intracontinental sea on a waterway between the Mediterranean Sea and the Black Sea. It is lined in both the North and the South by Turkey and is extended over a surface of 11, $500 \mathrm{~km}^{2}$. The Sea of Marmara is divided into three pull-apart basins, these are from West to East Tekirdag basin, Central basin and Çinarcik basin with a maximum depth of 1,152 $\mathrm{m}, 1,265 \mathrm{~m}$ and 1,273 $\mathrm{m}$ respectively. The basins are separated by NE-rending ridges, the Central High and the Western High, which were probably generated by shear strength and transpression controlled by the overall strain of the North Anatolian Fault (NAF) (Okay et al., 1999). The Sea of Marmara is also crossed by branches of the the North Anatolian Fault, a plate boundary between the Anatolian and the Eurasian plates (Le Pichon et al., 2001). This fault zone is one of the most active and the most dangerous amongst the European faults. It is composed of several segments, which have undergone several major earthquakes during the twentieth century. The last major ones are 1999 Izmit and Duzce earthquakes (Barka et al., 2002; Gasperini et al., 2011; Utkucu et al., 2003).

Stratigraphic analysis of Late Quaternary sediments of the Sea of Marmara indicates that it was a freshwater lake during the last glacial period $12 \mathrm{kyr} 14 \mathrm{C}$ Before Present (BP) (14.7 ka BP) (Aksu et al., 2002; Cagatay et al., 2000; McHugh et al., 2008; Vidal et al.). After its reconnection with the Mediterranean about $12 \mathrm{kyr} 14 \mathrm{C}$ BP the sea level in the Sea of Marmara rose in tandem with the global ocean. The mixing of the anoxic lake deep water and oxygenated marine surface water caused the precipitation of authigenic carbonates (Reichel and Halbach, 2007). A sapropelic sediment layer was deposited between 11,500 and 7,000 yr BP under suboxic bottom water conditions. Following marine flooding, two sapropelic sediment layers were deposited during 10,600 - 6,400 and 4,750 - 3,200 a 14C BP under suboxic bottom water conditions. (Çağatay et al., 1999, 2000).

Our area of interest is the Western High, situated between Tekirdag and Central basins. It is a complex geological feature along the northern branch of the NAF, characterized by a mud diapir. A carbonate and a hydrate mounds as well as active cold seeps with gas bubbling to the seafloor are the major features which have been identified at this area (Tryon et al., 2010; Zitter et al., 2008).

\section{Experimental section}

Three gravity cores, MARM_1, MARM_2 and MARM_3, were used for this study as illustrated in Figure 1. MARM_3, with a length of about $100 \mathrm{~cm}$, collected during the Marnaut scientific expedition, was the only core full of gas hydrates that were sampled and analyzed. MARM_1 and MARM_2, with a length of $248 \mathrm{~cm}$ and $418 \mathrm{~cm}$ respectively, were collected during the MARMARA 2010 cruise, did not contain any massive hydrates. The location of these cores was chosen from multichannel seismic profiles and previous studies of the site. MARM_1 and MARM_2 were immediately cut into segments of $1 \mathrm{~m}$ length and stored at $4{ }^{\circ} \mathrm{C}$ prior to being sampling. MARM_1 was used as reference core as it was located away from the gas vent and did not show any visual evidence of neither hydrates nor released gas bubbles. Gas bubbles were also sampled directly from a gas vent on the seafloor close to MARM_2 by the manned submarine Nautile during the Marnaut cruise and has been studied by Bourry et al. (2009). 


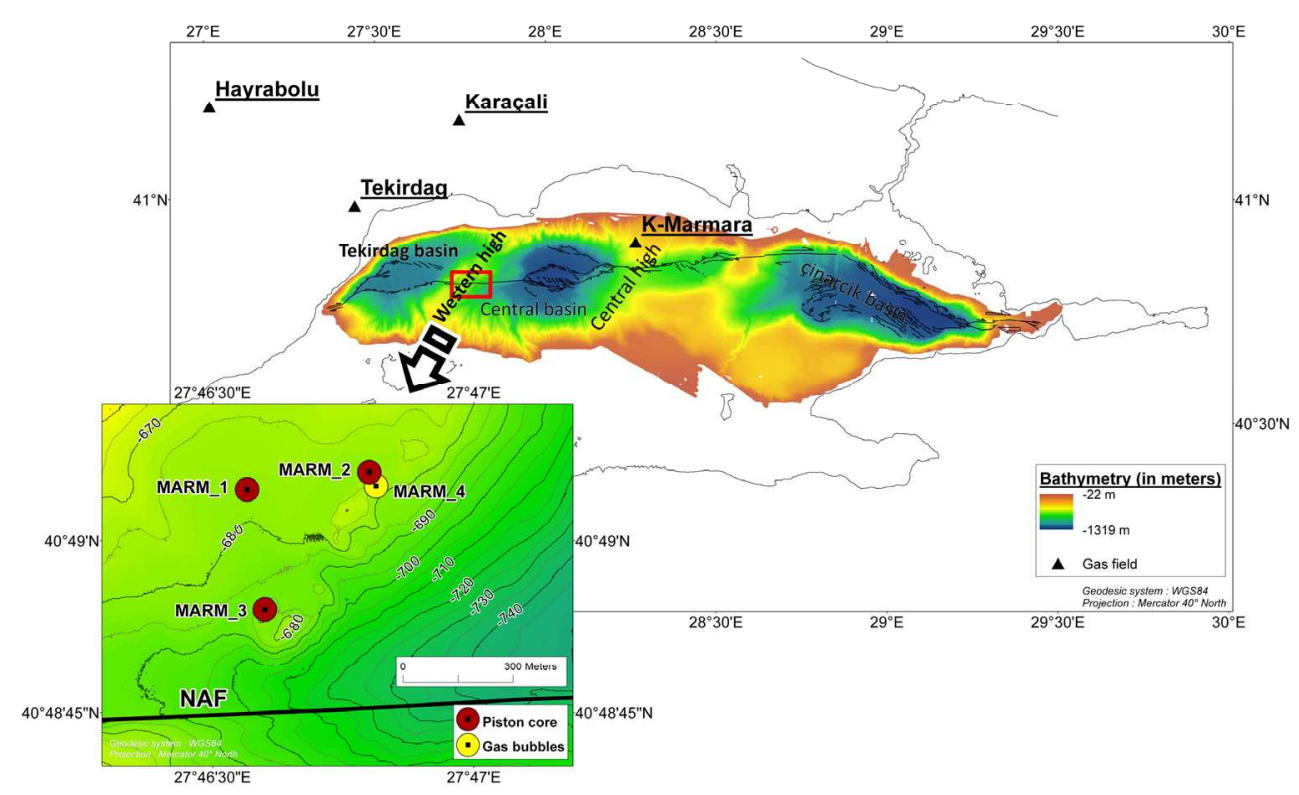

Fig. 1. General map of the Sea of Marmara indicating the locations of major features, the coring sites on the Western High and the natural gas fields.

\subsection{Core analyses}

On shore, the cores MARM_1 and MARM_2 were scanned using a medical X-ray CT Scanner Philips, model MX $80003^{\text {rd }}$ generation. The complete scan for each entire $1 \mathrm{~m}$ length section was performed in about 10 minutes and consists of more than 1,000 slides of $2 \mathrm{~mm}$ thick took every $1 \mathrm{~mm}$. The core sections were then split in two halves, working half and archive half, for further sampling and analyses. The archive halves were analysed using a Xray fluorescence $(\mathrm{XRF})$ core scanner from Aavatech to determine variations in its bulk chemical composition (Richter et al., 2006).

\subsection{Gas hydrate sampling and analyses}

The gas-hydrate specimens had a diameter of about $8 \mathrm{~cm}$. As shown in Figure 2, the hydrates had a well-defined yellow colour and were mixed with a small amount of sediment. The hydrates as well as the sediment were completely stained with oil (Figure 2), with a yellow colour which is a consequence of the presence of the oil. All recovered pieces were stored in liquid nitrogen at $77 \mathrm{~K}$ to avoid further decomposition before being analysed in the laboratory. 

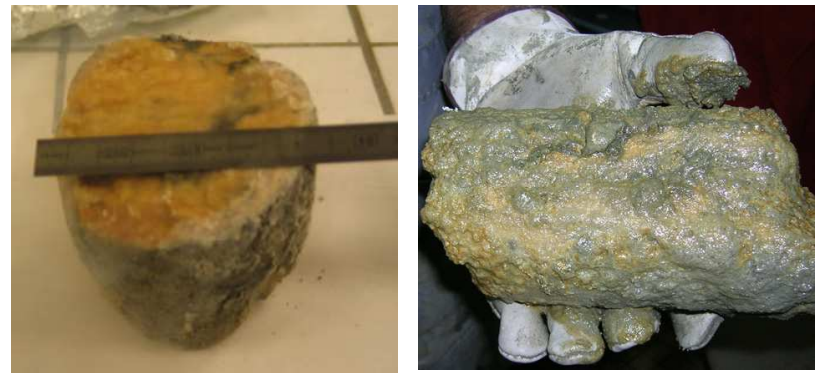

Fig. 2. Pictures of the recovered gas-hydrate specimens. The hydrates were massive and mixed with oily sediment.

For the analyses of the hydrate-bound gases, small pieces of hydrates were allowed to dissociate in a $20 \mathrm{~mL}$ glass tube which was previously evacuated. The gases were extracted from the hydrate samples using a gas extraction set-up (Charlou et al., 2004), and the hydrate water was collected and stored in another $20 \mathrm{~mL}$ glass tube. The resulting gases were also transferred into $10 \mathrm{~mL}$ glass tubes at a pressure ranging between 2 and 3 bars. Gas composition determination was carried out at the Laboratoire de Géochimie et Métallogénie of IFREMER.

For gas compositional analysis, the glass tubes were directly connected to a 6-port sampling valve of a 7890A Agilent gas chromatograph coupled with an Agilent 5975C quadrupole mass spectrometer detector (GC-MS). A custom-made instrument was used. It is equipped with a TCD-FID-mass detector and two capillary columns, Pora PLOT Q and molecular sieve, which can be put in series for the analysis of both hydrocarbons and permanent gases such as nitrogen and oxygen from the air. The analyses were performed with a temperature program running from $313 \mathrm{~K}$ to $500 \mathrm{~K}$. Helium was used as a carrier gas. Both the TCD and FID were used for quantitative analyses while the mass spectrometer detector was used for a qualitative purpose. In the latter case, the compounds were identified using the NIST02 mass spectral library and only those giving a confidence in the identification exceeding $90 \%$ have been selected and listed. The response of the TCD and FID were calibrated using a commercially-prepared gas mixture from Air Liquide. Considering the reproducibility of the gas chromatography measurements, the uncertainty in the calibration and the correction to eliminate the admixture of air, we estimated the accuracy in the composition measurement to be within $\pm 3 \%$ of the molar fraction. The lower detection limit is estimated to $0.05 \mathrm{nmol}$ for the hydrocarbons.

Isotopic measurements were carried out with a gas chromatography-isotope ratio-mass spectrometer (GC-IR-MS) at Isolab Laboratory, the Netherlands. The $\delta^{13} \mathrm{C}$ values and the $\delta \mathrm{D}$ are reported as parts per thousand (\%o) relative to the Vienna PeeDee Belemnite Standard (VPDB) and the Vienna Standard Mean Ocean Water (VSMOW) respectively. The uncertainty in $\delta^{13} \mathrm{C}$ and $\delta \mathrm{D}$ are given as \pm 0.1 to $0.3 \%$ and \pm 1 to $3 \%$ respectively.

\subsection{Pore-fluid sampling and analyses}

For each section of MARM_1 and MARM_2, the pore fluids have been sampled for chemical analyses using the Rhyzon ${ }^{\circledR}$ soil moisture samplers. This is an innovative water extraction 
technology on which the sampler consists of a hydrophilic, porous polymer tube of $2.5 \mathrm{~mm}$ in diameter and $50 \mathrm{~mm}$ length. The tube is introduced into the sediment from one end, and is permanently connected to a vacuum tube of $\sim 10 \mathrm{~mL}$ from the other end where the pore fluid is collected. The samplings were performed with a resolution of about 20 or $30 \mathrm{~cm}$. Alkalinity was measured on ship directly after the sampling. Thus, $1 \mathrm{~mL}$ of pore fluid was sampled and analysed by direct titration with ultrapure $0.1 \mathrm{~N} \mathrm{HCl}$ in an open cell.

The major dissolved elements were analysed by ionic chromatography using a Dionex ICS2000 instrument equipped with ACS autosampler. For the analyses of sulphate and chloride, an AS-17C column of $250 \mathrm{~mm}$ in length and $4 \mathrm{~mm}$ in diameter was used with a $4 \mathrm{~mm}$ ASRS suppressor. The detection limit was $1.5 \mathrm{ppm}$ and $5 \mathrm{ppm}$ for the sulphate and the chloride, respectively. For all cations, an Ionpac CS12A column of $250 \mathrm{~mm}$ length and $4 \mathrm{~mm}$ in diameter was used with a CAES suppressor. The detection limit was $0.1 \mathrm{ppm}$ for all species. All peak areas were quantified against equivalently diluted International Association for Physical Sciences of Oceans (IAPSO) standard seawater; the latter was analysed at the beginning of each run. The estimated accuracy on the concentration measurements is within $\pm 3 \%$ of the mole fraction for all ions.

The strontium isotope ratio measurements were carried out using a Neptune multicollector inductively coupled plasma mass spectrometer (MC-ICPMS) from Thermo Scientific. A volume of $125 \mu \mathrm{l}$ of sample was taken and mixed up with $1 \mathrm{~mL}$ of nitric acid 5 $\mathrm{N}$ in a SAVILLEX beaker placed on a hotplate at $373 \mathrm{~K}$ overnight. The residual phase was reacidified with $0.5 \mathrm{~mL}$ of nitric acid at $3 \mathrm{~N}$, then loaded onto a column containing a preconditioned crown ether cation exchange resin Sr Spec from EICHROM. The column was previously washed with $2 \mathrm{~mL}$ of distilled water (Milli-Q), then $1 \mathrm{~mL}$ of nitric acid 3 $\mathrm{N}$. The elution was done with $2.5 \mathrm{~mL}$ of nitric acid $3 \mathrm{~N}$ and the Strontium collection with 4 $\mathrm{mL}$ of nitric acid $0.01 \mathrm{~N}$ followed by $1 \mathrm{~mL}$ of distilled water. After a new evaporation step, the solid-state sample was dissolved in $0.5 \mathrm{~mL}$ of a mixture of nitric acid $2 \%$. The row results were normalized using the NIST 987 standard and we came up with accuracy better than 0.00004 .

\subsection{Sediment sampling and analyses}

The sediment was sampled within 1 hour after splitting the core sections. Slides of $2 \mathrm{~cm}$ thickness were taken with a resolution of $10 \mathrm{~cm}$. The collected samples have been analysed using both X-ray fluorescence and X-ray diffraction techniques (XRF, XRD). X-ray fluorescence was used in order to quantify the bulk chemical composition, i.e the present major, minor and trace elements in order to complement the XRF core-scanner analysis whereas X-ray diffraction enabled the identification of the various mineral phases as well as the evaluation of their ratio. The preparation of the sediment samples was as follows: the samples were finely crushed in powder and then dried overnight in an oven at $110^{\circ} \mathrm{C}$. For the identification of the mineral phases by XRD, a part of the prepared powder was directly taken, put in a sample holder where the surface sample was made flat by using a glass slide, then analysed.

The remaining powder was transformed into both fusion beads and compressed powder pellets for XRF analysis. The fusion beads allow for accurate measurements of major and 
minor element content (i.e. mass concentration $>0.1 \%$ ) while the compressed powder pellet is used for the analysis of trace elements (mass concentration $<0.1 \%$ ). The fabrication of the fusion beads was as follows: the powder was calcinated under air at $1,050^{\circ} \mathrm{C}$ in a platinum cup for $1 \mathrm{~h} 30$ (Loss of Ignition, LOI which corresponds to the loss of carbonate and sulphite ions). After removal and cooling, the sample was crushed a second time. A precise amount of $0.50000 \mathrm{~g}$ was taken and mixed with exactly $9.000 \mathrm{~g}$ of flux of $90 \%$ lithium tetraborate $\left(\mathrm{LiB}_{4} \mathrm{O} 7\right)$ and $10 \%$ of lithium fluoride $(\mathrm{LiF})$. Then, $500 \mathrm{~mL}$ of lithium bromide solution $(250 \mathrm{~g} / \mathrm{L} \mathrm{LiBr})$ is added by pipetting, and the mixture was dried again. It was then placed in a gold-platinum crucible and put in the oven at $1,050^{\circ} \mathrm{C}$ for $15 \mathrm{~min}$. Finally, the resulting solid solution was removed from the oven and re-homogenized to remove all bubbles. The crucible was put back in the oven for $10 \mathrm{~min}$. at $1,050^{\circ} \mathrm{C}$ and subsequently cooled at ambient temperature. After cooling, the fusion beads were ready for analysis. The powder pellets were made by mixing $4 \mathrm{~g}$ of sediment sample with $0.4 \mathrm{~g}$ of wax (Hoechst type $\mathrm{C}$ ). The resulting mixture was introduced into a mould and was compacted using a hydraulic press at $10 \mathrm{~T} / \mathrm{cm}^{2}$.

The wavelength dispersive X-ray fluorescence spectrometer used here was a S8 TIGER, BRÜKER-AXS. The $X$ rays are absorbed by the sample, which thereafter emits wavelengths characterizing its composition. The instrument was calibrated using certified reference material (El Maghraoui et al., 1998). The X-ray diffraction analysis was performed with a diffractometer D8 ADVANCE BRÜKER-AXS with Bragg-Brentano geometry, using CuKa radiation with $\mathrm{Ni}$ filter at $35 \mathrm{kV}$ and $25 \mathrm{~mA}$ and angle from $5^{\circ}$ to $70^{\circ} 2 \theta$.

\section{Results and discussion}

\subsection{Composition and origin of the hydrate-bound gases and the gas bubbles}

Bourry et al. (2009) carried out isotopic, compositional and structural analyses of both the hydrate sample and the gas bubbles collected on the Western High. This work has provided the basic genetic characteristics of the hydrates and the related gases. The results from this work showed that the hydrate-bound gases and the gas bubbles have a thermogenic origin. With about $90 \%$ methane and the remaining gases being heavier hydrocarbons and carbon dioxide, the molecular composition of the gas bubbles was representative of most of conventional natural gas. Our new measurements on the hydrate sample are in agreement with their values for both the isotopic and molecular compositions (Table 1). The hydratebound gases contain $65.2 \%$ methane, and a high amount of propane and isobutane (respectively $18.6 \%$ and $9.2 \%$ ). The mass detector of the GC-MS allowed us to detect cyclopentane, cyclohexane, 3-Methylpentane, 2-3-DiMethylbutane, benzene, MethylCyclopentane and Trans 1-4-DiMethyl-cyclohexane in the hydrate-bound gases. Those compounds have not been quantified and are presumably in small amount; therefore they are not taken into account in the hydrate composition in Table 1. As can be calculated from Table 1, the $\mathrm{C} 1 /(\mathrm{C} 2+\mathrm{C} 3)$ ratio is slightly above 3 and 24 for the hydrates and the gas bubbles, respectively. This is also indicative of thermogenic gases. These results are in coherence with the yellow tint of the recovered hydrate specimens, reflecting the petroleum fingerprint. Figure 3 summarises the genetic characterization of both the hydrate-bound gases and the gas bubbles. The CD diagram, based on the carbon and hydrogen isotopic composition of the methane (Schoell, 1983; Whiticar, 1994), indicates a thermogenic gas 


\begin{tabular}{cccccc}
\hline \multicolumn{5}{c}{ Gas hydrate sample } & \multicolumn{3}{c}{ Gas bubbles (after Bourry et al., 2009) } \\
\hline \multirow{2}{*}{ Components } & $\%$ Mole fraction & $\begin{array}{c}\delta^{13} \mathrm{C}(\% \mathrm{o} \\
\mathrm{PDB})\end{array}$ & $\begin{array}{c}\delta^{13} \mathrm{D}(\% \mathrm{o} \\
\mathrm{SMOW})\end{array}$ & $\begin{array}{c}\% \text { Mole } \\
\text { fraction }\end{array}$ & $\delta^{13 \mathrm{C}}(\% \mathrm{oDB})$ \\
\hline $\mathrm{C} 1$ & 65.2 & -43.7 & -222 & 90.90 & -44.4 \\
$\mathrm{C} 2$ & 1.5 & -23.5 & -106 & 1.23 & -25.7 \\
$\mathrm{C} 3$ & 18.6 & -21.6 & -146 & 2.50 & -21.1 \\
$\mathrm{iC} 4$ & 9.2 & -27.8 & -163 & 0.93 & -28 \\
$\mathrm{nC} 4$ & 0.18 & - & - & 0.15 & 20.1 \\
neoC5 & 0.049 & -25.2 & -199 & 0.0034 & - \\
$\mathrm{iC5}$ & 0.037 & -26.2 & - & 0.31 & -25.3 \\
$\mathrm{nC5}$ & - & - & - & 0.010 & -18.9 \\
$\mathrm{C} 6+$ & 0.22 & - & - & 0.0017 & - \\
$\mathrm{CO}_{2}$ & 5.1 & +27.3 & - & 3.90 & +29.1 \\
\hline
\end{tabular}

Table 1. Molecular and isotopic compositions of the hydrate-bound gases and the gas bubbles

a)

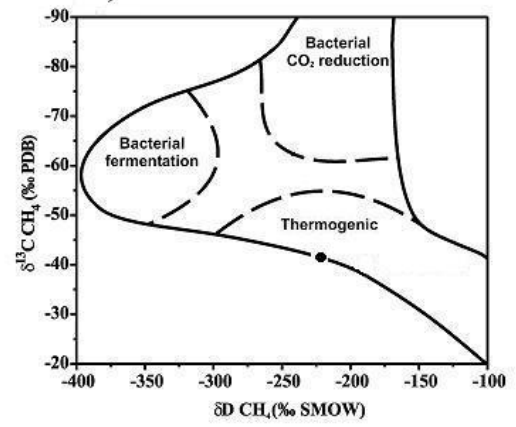

b)

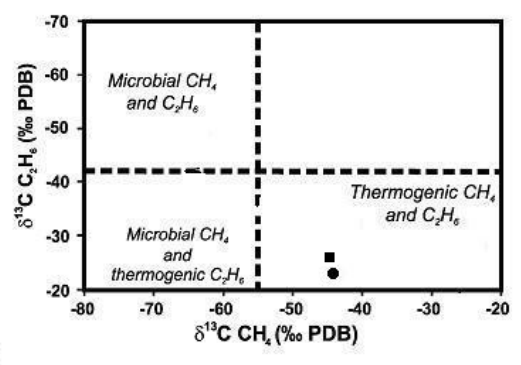

c)

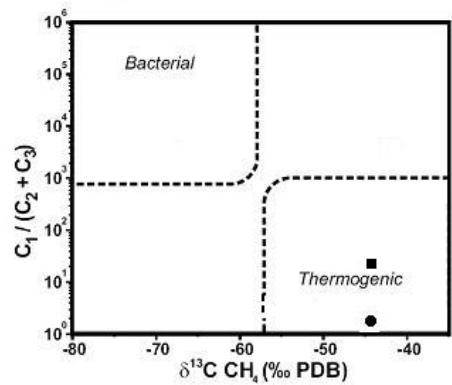

Fig. 3. a) Plot of hydrogen and carbon isotope compositions for the gas-hydrate sample indicating a thermogenic origin of methane (diagram modified after Schoell, 1983), b)

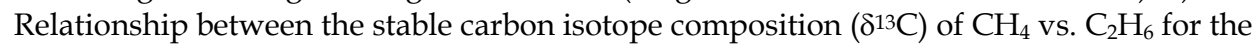
hydrate-bond gases and the gas bubbles. $\mathrm{CH}_{4}$ and $\mathrm{C}_{2} \mathrm{H}_{6}$ have a thermogenic origin (diagram modified after Bernard, 1978), c) Relationship between methane carbon isotope composition vs. ethane and propane molecular composition (diagram modified after Bernard, 1978). (•) gas-hydrate sample, (๘) gas bubbles. 
which is close to the boundary with the geothermal, hydrothermal and crystalline zone, while both Bernard diagrams (Bernard et al., 1978) plot the hydrate-bound gases and the gas bubbles well inside the thermogenic zone. Thus, the natural gas of the Western High comes from at least one hydrocarbon reservoir.

The unique petroliferous area present nearby is the Thrace basin. It is the major gas producing province of Turkey which extends to the northern part of the Sea of Marmara (Gürgey, 2009; Gürgey et al., 2005; Hoşgörmez and Yalçin, 2005; Hoşgörmez et al., 2005). Therefore it is likely that the natural gas comes from deep-subsurface hydrocarbon reservoirs of this basin and feeds the Natural-Gas Hydrate Occurrence Zone (NGHOZ) of the Western High. Accordingly the gas bubbles and the hydrate-bound gases could share the same source rock.

A large amount of research investigations based on geology, petroleum geology, stratigraphy, geophysics and petroleum geochemistry have been carried out to better understand and describe the Thrace basin petroleum system (Coskun, 1997; Coskun, 2000; Gürgey, 2009; Gürgey et al., 2005; Hoşgörmez and Yalçin, 2005; Hoşgörmez et al., 2005; Şen Şamil et al., 2009). Hoşgömez et al. (2005) have combined isotopic and molecular composition analyses of light alkanes along with basin modelling in order to determine the source rocks of the hydrocarbon fields discovered there. Their results agree and complement those of Gürgey et al. (2005). Overall, they showed that (1) the thermogenic gas in the Thrace basin could come from two different types of source rock: a mature source which consists of a mixed type of organic matter (marine and terrestrial), and another which is an early mature source with marine organic matter, (2) the gas can be classified in three groups: Group I consists of pure thermogenic gases generated by a mixed type of organic matter. Group II is the result of mixing of a fraction of the thermogenic gases from group I with microbial gases. Group III is a mixture of at least two different thermogenic gases, one being the thermogenic gases of Group I and the other one is a marine source rock, (3) there are two potential source rocks for the studied natural gas fields: the Hamitabat formation (Middle Eocene) and the Mezardere formation (Upper Oligocene), (4) the Hamitabat formation is the source rock of K-Marmara natural-gas field, which consists of pure thermogenic gases while the Mezardere formation is the source rock of thermogenic portion of the natural-gas fields containing both thermogenic and microbial gases.

The gas bubbles from the Western High might be genetically linked to one of these source rocks, or be independent of the onshore petroleum systems. Some similarity in molecular composition has been highlighted with the studied gas fields, especially with the KMarmara natural-gas field (Bourry et al., 2009). The latter consists of pure thermogenic gases (Figure 4b). However, when applying the Chung's diagram (Chung et al., 1988) to both the hydrate-bound gases and the gas bubbles, it appears that they consist of a mixture of thermogenic and microbial gases (Figure 4a) as we came up with a concave down curve instead of a straight line as for pure thermogenic gases. Amongst all natural-gas fields studied by Hoşgörmez and Yalçin (2005), three fields, Tekirdag, Karacali and Hayrabolu, contain a mixture of thermogenic and microbial methane like the gas bubbles (Figure $4 \mathrm{~b}$ ). All three fields also have the same source rock which is the Mezardere formation. Therefore they or their source rock may also be considered as a potential candidate for the source of the hydrate-forming gases and the gas bubbles.

Figure $4 \mathrm{~b}$ shows that the gas bubbles and the hydrate-bound gases have a source rock which is isotopically heavier ( - $15 \%$ ) than the natural-gas fields $(-21 \%)$. The difference between the two projected source rocks could be due to the heterogeneities in the precursor kerogen, 

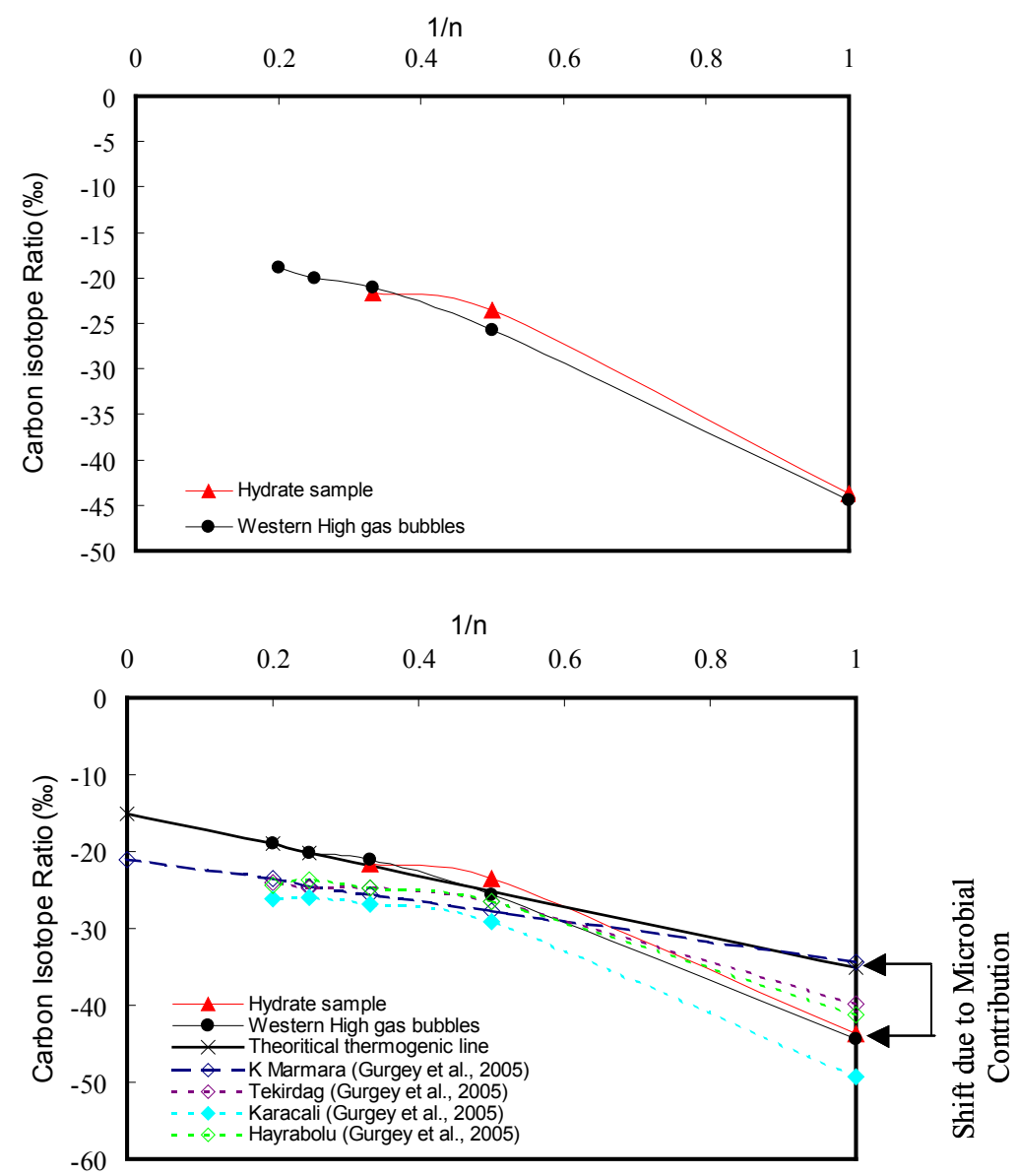

Fig. 4. Gas plot model based on the reciprocal of the carbon chain length against the $\delta^{13} \mathrm{C}$ of the respective hydrocarbons (after Chung et al., 1988). a) The non-linearity of the curve is indicative of mixing between thermogenic and microbial gases. b) Comparison between the Western High gases and three natural-gas fields of the Thrace basin.

or the gas generation mechanism (Pohlman et al., 2005). One can also see that the projected pure thermogenic methane of all gases matches with the thermogenic methane from the KMarmara natural gas. Thus, we believe that a portion of the methane of all the natural-gas seeps presented here comes from the same source rather than the K-Marmara natural gas, namely the Hamitabat formation. However, the origin of the remaining portion is still elusive.

Table 1 shows that the isotopic signature of carbon dioxide for the studied gases differs a lot from that of the previously mentioned natural-gas fields and this may be a key for the interpretation of the gas source. The positive value of $\delta^{13} \mathrm{C}$ of carbon dioxide for both the hydrates $(+27.3 \%$ ) and the gas bubbles $(+29.1 \%$ ) contrast with the negative values 
$(-9.9 \%$, $-11.5 \%$, $-8.5 \%$ o $)$ of the respectively Tekirdag, Karacali and Hayrabolu naturalgas fields (Hoşgörmez et al., 2005). Hence, it is unlikely that the gas bubbles may come from directly those natural-gas fields. $\delta^{13} \mathrm{C}$-enriched $\mathrm{CO}_{2}$, with values above $+5 \%$, are typically due to secondary methanogenesis following hydrocarbon biodegradation occurring in petroleum reservoirs or during secondary and tertiary migration (Etiope et al., 2009b). The secondary methanogenesis increases the $\delta^{13} \mathrm{C}$ of residual $\mathrm{CO}_{2}$ (previously produced by anaerobic oxidation of heavy hydrocarbons) which may easily exceed $+10 \%$ o (Etiope et al., 2009b; Pallasser, 2000). Petroleum biodegradation process is a phenomenon that was neglected in the past, but today it is considered to affect a large fraction of conventional oil reserves (Dimitrakopoulos and Muehlenbachs, 1987; Head et al., 2003; Jones et al., 2007). Such a biodegradation typically modifies also propane and other nalkanes isotopic values, leading to large isotopic separations between successive n-alkanes and high C2/C3 and/ or iC4/nC4 ratios (Etiope et al., 2009a; Etiope et al., 2009b; Waseda and Iwano, 2008). Therefore, the isotopic and molecular compositions of the gas bubbles and the hydrate bound-gases show that they meet the requirements of seeps which have undergone a biodegradation at the reservoir level along with a secondary methanogenesis (Etiope et al., 2009b).

The application of the model developed by Berner and Faber (Berner and Faber, 1996) to the different natural-gas seeps leads to the same conclusions (Figure 5).
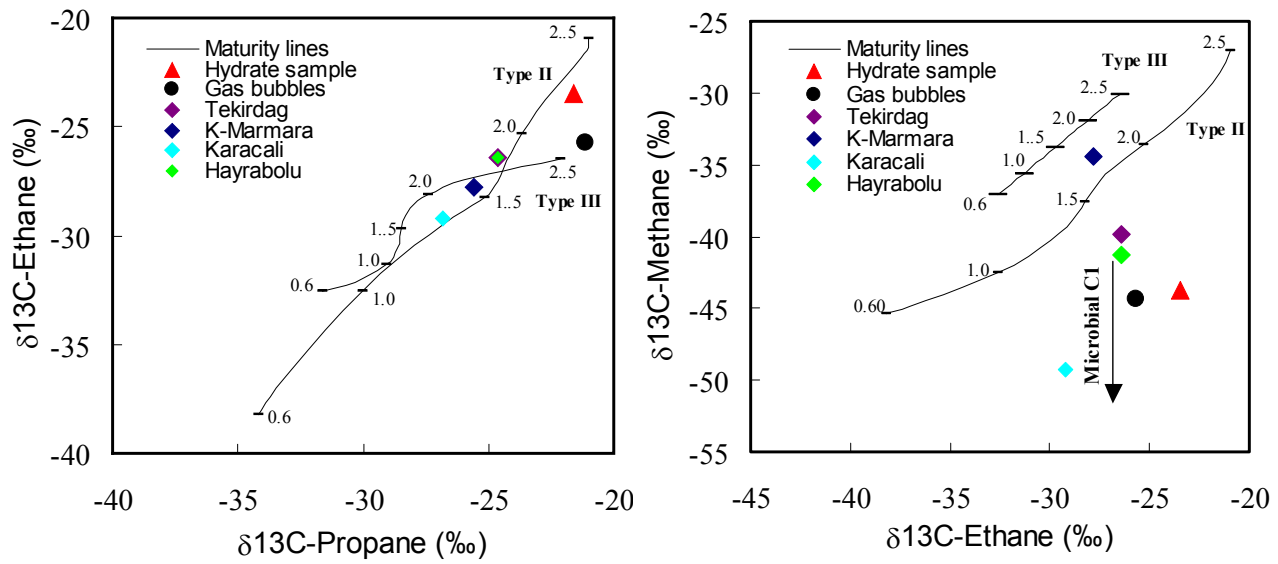

Fig. 5. Genetic characterization of the gases based on the $\delta^{13} \mathrm{C}$ of the couples propane- ethane and methane- ethane (modified after Berner and Faber, 1996).

The shift towards heavier $\delta^{13} \mathrm{C}$ for the propane indicates that the gases are biodegraded (Figure 5a). The source rock is primarily type II kerogen and the generated gases reflect overmaturity (Ro >1.7). This is consistent with the generation of oil as well as gas in the oil window (Berner and Faber, 1996). Figure 5b presents the level of mixing of microbial methane with the thermogenic one. In the case of both the gas bubbles and the hydrateforming gases, this shift downwards represents the microbial contribution which is due to the methanogenesis following the biodegradation. 
Following the analyses presented above, it is likely that the origin of both the hydrate-bound gases and the gas bubbles studied here is the source rocks supplying the same thermogenic gases that the onshore natural-gas fields. However the hydrocarbons accumulated underneath the Western High underwent a biodegradation, which is not observed for the onshore-fields. It seems that both the Hamitabat and the Mezardere formations could contribute to the supplying of the gases as both formations have reached the expected maturity level for the gas generation. These formations could first supply a reservoir in which biodegradation of oil and methanogenesis occur. The latter process leads to the production of microbial methane at the reservoir level. However the occurrence of these combined processes, biodegradation/ methanogenesis, requires a reservoir at a depth of less than $2000 \mathrm{~m}$ and a temperature between 343.15 and 353.15 K (Gürgey et al., 2005).

Presently, it is not possible to link the gas bubbles as well as the hydrate-bound gases to any known offshore reservoirs, and unfortunately there are no available geologic cross sections or published stratigraphic columns for the offshore southern Thrace basin. Petroleum exploration has been made at the southwestern part of the Thrace basin, onshore as well as offshore in Sea of Marmara. After drilling several wells, it turned out that all of them were dry (Sen et al., 2009). A specific study and reconstruction of the Thrace basin sedimentary formations towards the Sea of Marmara should be made, starting from seismic data. It would be essential to verify the position and setting of the formations and the eventual occurrence of reservoirs in the Sea of Marmara.

\subsection{Hydrate formation driven by gas/fluid migration and associated mineralization}

\subsubsection{Gas migration and hydrate formation}

The study of the gas bubbles and the hydrate-bound gases revealed that both have primarily a thermogenic origin. By applying the CSM-GEM model (Sloan and Koh, 2008), it has been showed that the gas bubbles are representative of the hydrate-supplying gases (Bourry et al., 2009). The abundances of propane and isobutane along with methane are diagnostic of structure II (Sloan and Koh, 2008), and that has been confirmed by Raman spectroscopy (Bourry et al., 2009). However, the inclusion of heavier hydrocarbons such as the identified cyclo- $\mathrm{C}_{5+}$ and Methyl- $\mathrm{C}_{4+}$ suggests the possibility of having structure $\mathrm{H}$ (Lu et al., 2007; Sassen et al., 1999). Moreover, owing to the presence of a large amount of propane and isobutane, at that depth and temperature conditions, the hydrate accumulation is well inside its thermodynamic stability field. Thus, its destabilisation would occur by a dissolution process in the pore fluid rather than by a dissociation with release of gas bubbles (Sultan et al., 2010). Therefore, it is likely that the gas bubbles sampled nearby are the manifestation on the seafloor of the natural-gas migration from deep-hydrocarbon reservoirs through the fault system of the Western High.

Figure 6 represents the 3D images obtained from the X-ray CT scan analysis of the recovered cores MARM_1 and MARM_2. The uppermost segments of both cores, segments with a length of $48 \mathrm{~cm}$ and $18 \mathrm{~cm}$ for MARM_1 and MARM_2, respectively, have not been scanned. A network of cracks where gases and fluids can migrate and accumulate characterizes both cores. The first scanned segment of MARM_1 (Figure 6, MARM_1 a) and a')) contains a "light" sediment which was quite difficult to image in 3D. Thus, Figure 6 MARM_1 b) represents the core liner with no possibility of seeing through. The image $\left.\left(a^{\prime}\right)\right)$ represents a 

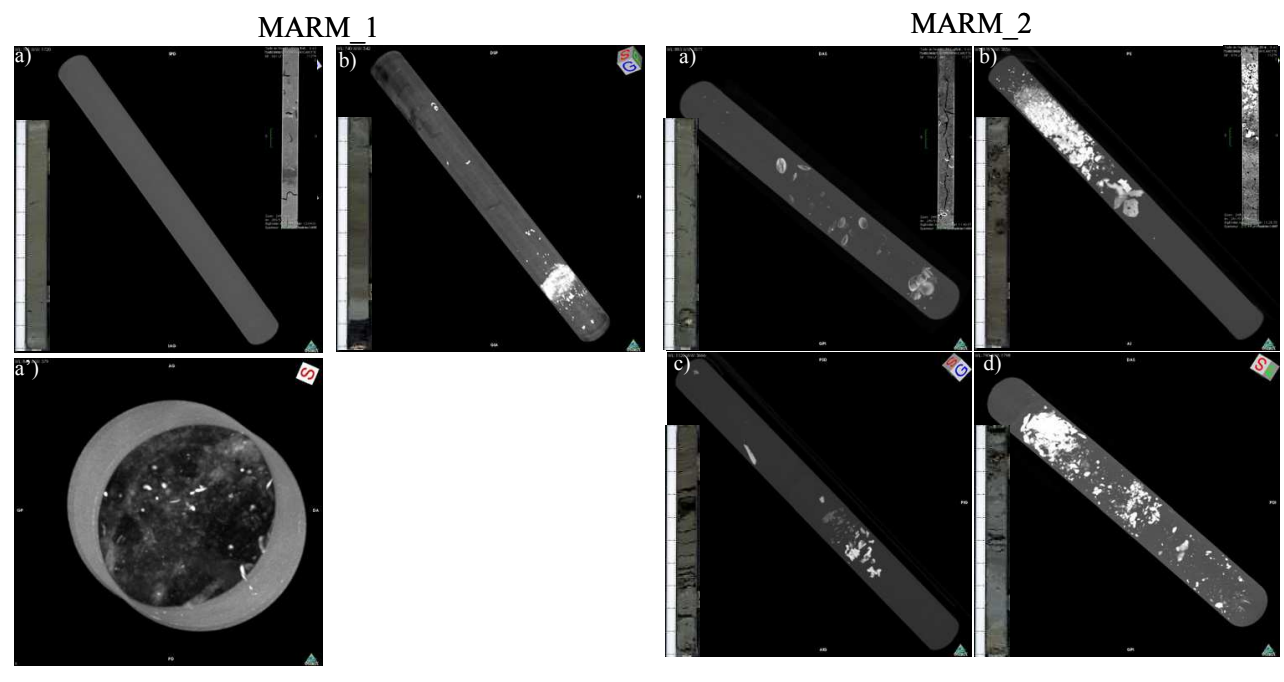

Fig. 6. CT scan images along with core photography of MARM_1 and MARM_2.

front view of the said core-segment which clearly show a lighter sediment and scattered with some concretion-like phases. The second scanned segment of MARM_1 is characterized by a very black sulphidic sediment at its lower part (from $238 \mathrm{~cm}$ to the end) which is located right underneath a denser carbonate-rich layer of about $8 \mathrm{~cm}$ thick (from $230 \mathrm{~cm}$ to the $238 \mathrm{~cm}$ ) captured in the 3D image (Figure 6, MARM_1 b)). It is most likely that the carbonate-rich level represents the lake/marine transition and the dark sulphidic sediments below are the lacustrine sediments. This is strengthened by the sulphur and the manganese profiles, as well as the iron concentration and the LOI from Table 3. The manganese profile presents two maximum peaks in concentration at $30 \mathrm{~cm}$ and $230 \mathrm{~cm}$, respectively. The latter depth also corresponds to the minimum in concentration of iron and a maximum in sulphur in the sediment for MARM_1 (Table 2). Such a behaviour is often related to the incorporation of manganese into the carbonate mineral found at that depth under oxic bottom sea water (Calvert and Pedersen, 1993; Schaller et al., 1997a; Schaller and Wehrli, 1996). The minimum in iron concentration could be explained by the formation of either Fecolloidal particles as a low level of pyrite was detected (Schaller et al., 1997b). The photography (Figure 6, MARM_1 b)) shows that the dense layer has a lighter grey-colour. Although dense, after splitting the section it turned out that this layer does not present any evidence of visible concretions. As illustrated in both the profiles of Figure 9 and Table 2, the calcium, strontium and barium exhibit a peak at about $230 \mathrm{~cm}$ which is probably related to the presence of carbonate mineral phases. Table 3 confirms the presence of calcite at this level. In the case of MARM_2, the positions of the different holes, bivalves and concretions in the photography of each segment are in good agreement with the resulting 3D images. The first section is characterized by the presence of bivalves with a build-up mainly at its lower part, while section 2 and 4 contained a large amount of carbonate concretions which were sampled after splitting the core. MARM_2 was taken near the gas seep and the crack network is a record of intense gas ebullition at this site. Each associated photography also shows a highly disturbed sediment where the concretion deposits are found. Furthermore, overall the XRF analyses showed high concentrations of $\mathrm{Si}, \mathrm{Al}$, and Fe which are ubiquitous 
in clay minerals (Tables 2 and 4). This is strengthened by the XRD analysis where several group of clay, such as kaolinite, smectite, illite and chlorite groups, have been identified in significant amounts (Tables 3 and 5). The results are also consistent with the previous sedimentology work carried out in this area (Bayhan et al., 2001). Usually natural-gas migration through faults in such a clay-rich marine sediment leads to the formation of massive, nodular or vein-filling hydrates (Holland et al., 2008; Paull and Dillon, 2001).

\subsubsection{Geochemical processes associated with the hydrate accumulation}

Hydrate accumulation in marine sediment is also associated with several biogeochemical processes (Boudreau, 1997; Luff and Wallmann, 2003; Schulz and Zabel, 2000; Wallmann et al., 2006). The analysis of selected elements from both the pore fluids and the sediment often provides useful indication on the occurrence of these processes, and accordingly helps in constraining the origin of the pore fluid which is involved in the formation and accumulation of the natural-gas hydrates. Figure 7 represents the pore-fluid profiles of selected dissolved-species. The analysis of the bottom seawater have not been made, however it is reasonable to assume that the composition is very close to the value found in the upper part of the cores. In Figure 8, the alkalinity and strontium isotope profiles of the pore fluid are shown along with the $\mathrm{Mg} / \mathrm{Ca}$ and $\mathrm{Sr} / \mathrm{Ca}$ ratios in the sediment and the pore fluid. The two cores exhibit very different pore-fluid profiles reflecting the heterogeneity of the system. The chloride concentration range from $475 \mathrm{mM}$ to $655 \mathrm{mM}$ for MARM_2 with a large scattering while MARM_1 presents a relatively constant concentration value with depth $(\sim 610 \mathrm{mM})$. The scattering for MARM_2 suggests the occurrence of hydrate dissociation and the value of $475 \mathrm{mM}$ is indicative of pore-fluid freshening due to this dissociation. For both cores, the dissolved sulphate decreases with depth. Along with methane, sulphate in pore-fluid is involved in the early diagenesis of marine sediments. Two chemical reactions lead to a depletion of sulphate concentration in anoxic conditions (Berner, 1980; Bhatnagar et al., 2008; Bhatnagar et al., 2011; Borowski et al., 1996; Borowski et al., 1999; Reeburgh, 1976):

- The microbial sulphate reduction (Martens and Val Klump, 1984). This process can be summarized in the following reaction:

$$
2\left(\mathrm{CH}_{2} \mathrm{O}\right)+\mathrm{SO}_{4}^{2-} \rightarrow 2 \mathrm{HCO}_{3}^{-}+\mathrm{H}_{2} \mathrm{~S}
$$

- $\quad$ The anaerobic oxidation of methane (AOM) by a consortium of microorganisms which consumes methane for their energy (Boetius et al., 2000) such as:

$$
\mathrm{CH}_{4}+\mathrm{SO}_{4}^{2-} \rightarrow \mathrm{HCO}_{3}^{-}+\mathrm{HS}^{-}+\mathrm{H}_{2} \mathrm{O}
$$

Equation (2) occurs at the sulphate-methane interface (SMI) in the sediment column which is characterized by high upward flux of methane and downward flux of seawater sulphate. This is the case on the Western High where methane-rich gas bubbles and natural-gas hydrates have been sampled. MARM_2 shows a linear decrease in the sulphate profile which is typical of the occurrence of sulphate reduction coupled with the anaerobic oxidation of methane (Hensen et al., 2003; Joye et al., 2004; Orcutt et al., 2004; Pohlman et al., 2008; Treude et al., 2003). The SMI is located at about $120 \mathrm{~cm}$ and corresponds to the depth where the sulphate concentration drops sharply to a value close to zero. Thus, below the SMI corresponds to a 
sulphate-free zone but rich in methane. The strong steep sulphate gradient from the seafloor to the SMI is a consequence of important upwards hydrocarbon fluxes (Borowski et al., 1996; Hensen et al., 2003). This is in agreement with the gas seep discovered there, as seep is a visible clue of intense upwards methane migration. The AOM process is very often associated with carbonate precipitation because it induces an increase in the total alkalinity (TA), which is directly related to the carbonate and sulphite ion concentrations of the pore fluid (see equation II). Once the pore-fluid saturation is reached, the carbonate formation begins and this is generally accompanied with variations in both pore-fluid and sediment profiles of $\mathrm{Ca}, \mathrm{Mg}, \mathrm{Sr}$. Accordingly, the study of the latter elements provides useful information on the carbonate diagenetic processes (Karaca et al., 2010; Ussler III et al., 2000). While it is observed a quite constant pore-fluid composition with depth for MARM_1, MARM_2 exhibits a decrease in Ca down to the SMI, then an increase up to about $250 \mathrm{~cm}$ depth followed by another decrease. The concentration of Mg constantly increases with depth for MARM_2. Moreover, one can see in Figure 8 that the TA of MARM_1 is constant with depth. However for MARM_2, the TA linearly increases to a shallow inflection at the SMI, then keeps increasing gradually with depth. The above lines of evidence suggest the occurrence of authigenic mineralization accompanied with mainly Ca removal from the pore fluid down to the SMI. This is consistent with carbonate precipitation. Here, the $\mathrm{Mg}$ profile exhibits an increase in concentration with depth. $\mathrm{Mg}$ is much more concentrated in modern seawater than $\mathrm{Ca}$, thus the concentrationdepth profile of the former is less sensitive to carbonate precipitation. Figure 8 shows the $\mathrm{Mg} / \mathrm{Ca}$ in both the sediment and the pore fluid as a function of depth for both cores, in both the sediment and the pore fluid. Beside the three points higher than 1 in the sediment which is presumably due to the presence of bivalves, these $\mathrm{Mg} / \mathrm{Ca}$ curves are nearly the conjugate of each other for both cores, i.e the ratio decreases in the pore fluid when it increases in the sediment. This is a consequence of authigenic carbonate precipitation that is typical for marine hydrate and methane-rich regions. Above the SMI, Ca in pore fluids drops sharply by calcite precipitation giving rise to the increase of $\mathrm{Mg} / \mathrm{Ca}$ ratio in pore fluid and the decrease in the sediment, while below, the precipitation of $\mathrm{Mg}$-rich minerals leads to the reciprocal behaviour.

The more common Mg-rich minerals encountered on a methane-rich sediment are the dolomite, high-Mg calcite and siderite. However, dolomite represents less than $5 \%$ weight of the mineral identified in MARM_2 whereas siderite has not been identified. Therefore, the Mg has probably been incorporated in the calcite. The increase with depth of the TA from the SMI to the lowest part of MARM_2 (Figure 8) could be a manifestation of upwards migration of fluids with high alkalinity, like hydrocarbon-reservoir brines migrating along with the gas bubbles. This would mean that a part of the pore fluid come from depth. The analysis of the radiogenic isotope of strontium can help us in constraining the sources and sinks of the fluid because its isotopes do not fractionate during geochemical processes (Kastner et al., 2008). As illustrated in Figure 8, MARM_1 has a fairly constant strontium isotope value with depth which is close to the modern seawater value ( 0.7092). For MARM_2, the fluid becomes less radiogenic with depth by a substantial amount. The value at its lowest part seems to be stabilized at $\sim 0.70877$. Therefore, these results strengthen the hypothesis of a deep source contribution of fluid. However, we do not have any other isotopic value available to compare with in order to better constraint the pore-fluid origin. An accurate determination of strontium concentration with depth combined with measurements on other geologic materials like the carbonates would help in gaining insights into the deep fluid source. That has to be considered for the continuation of this study. 


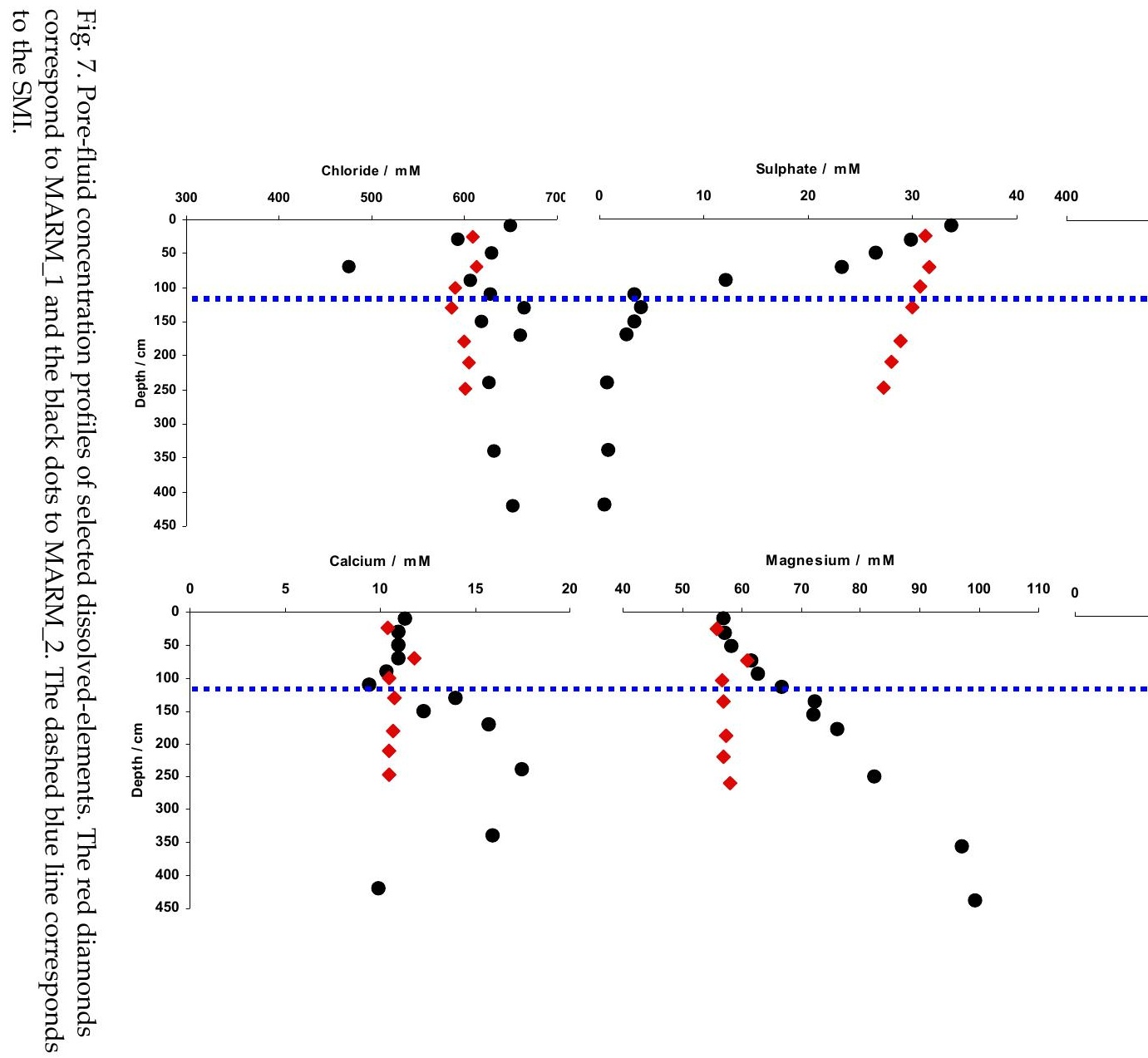




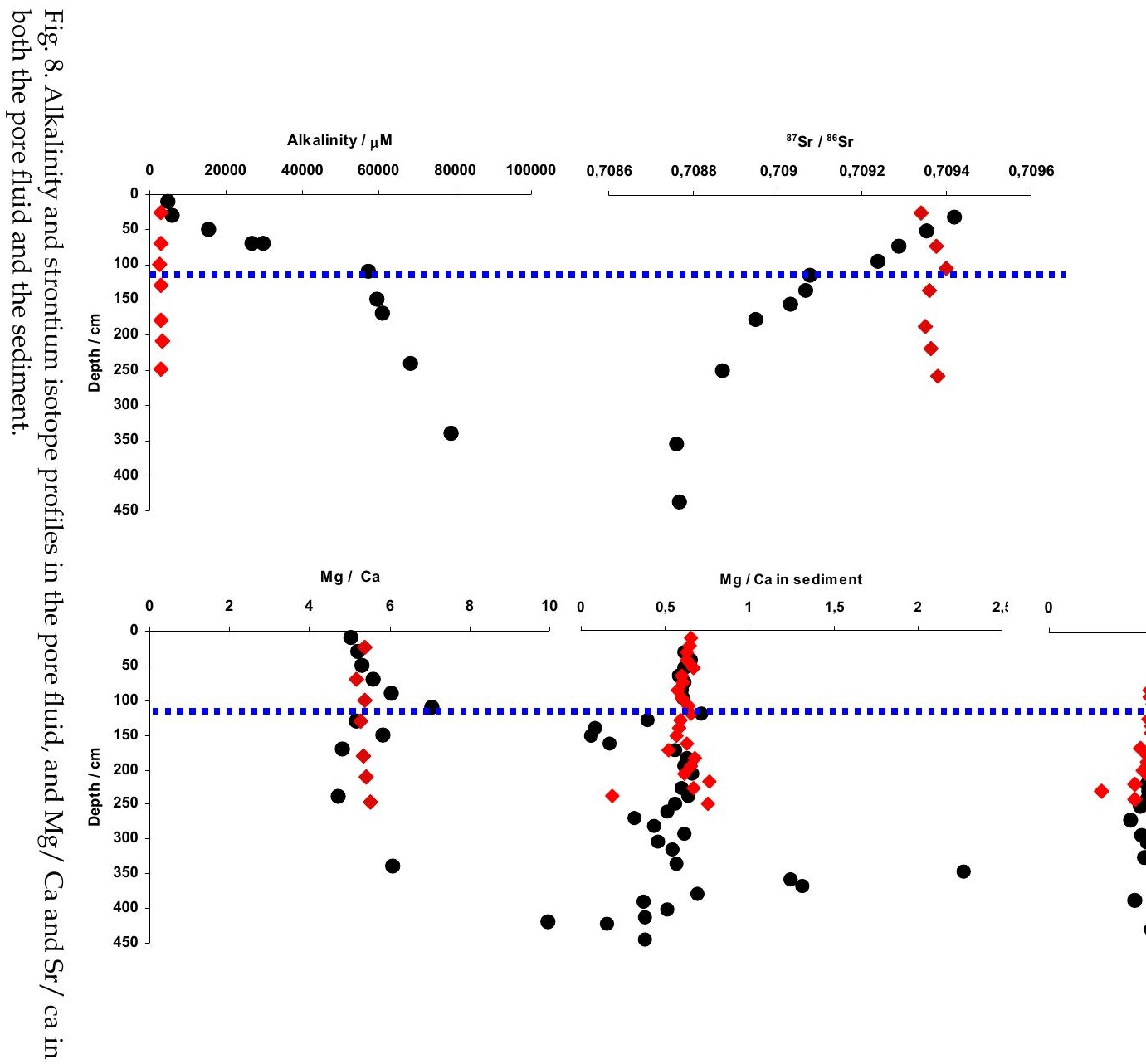




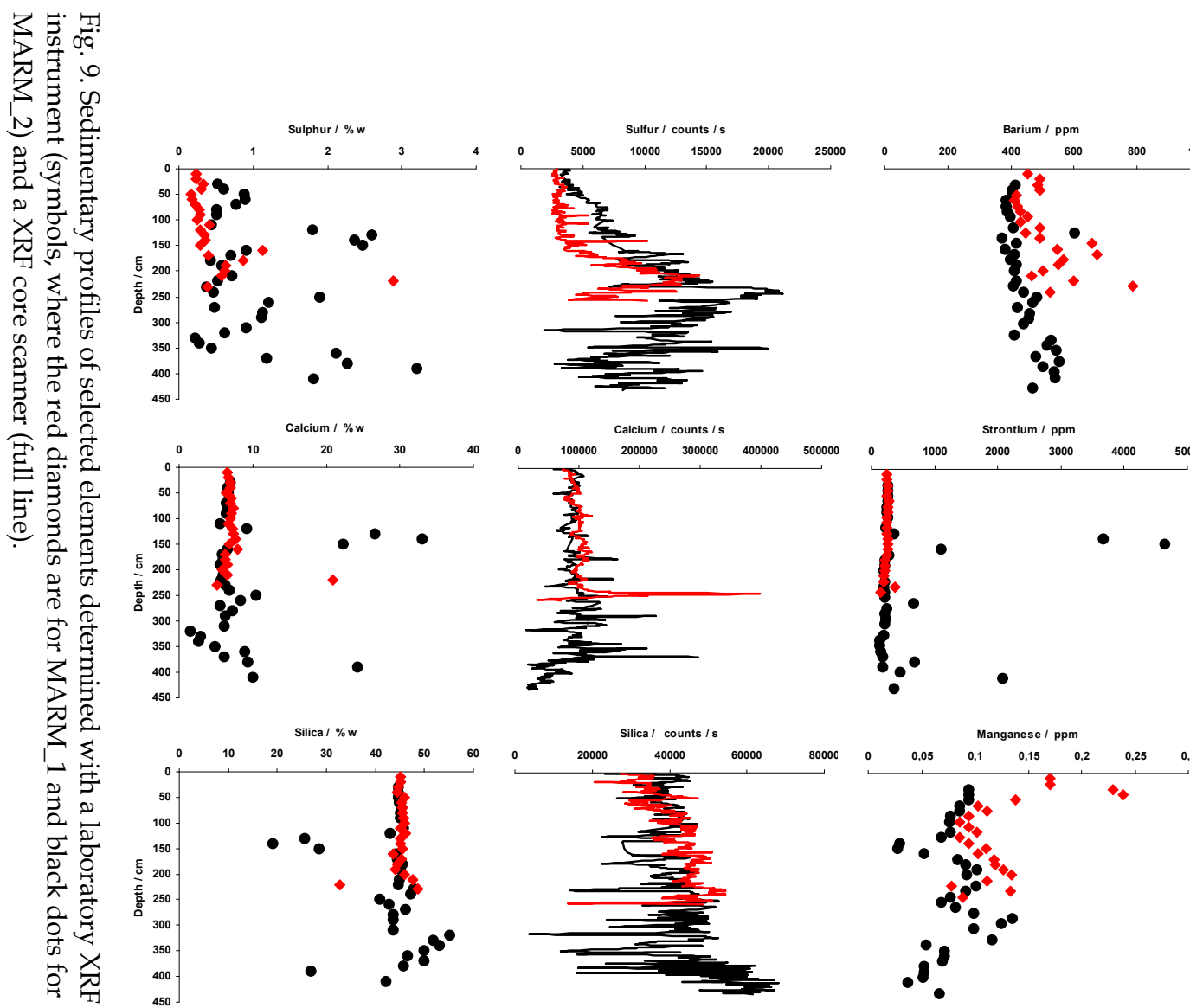




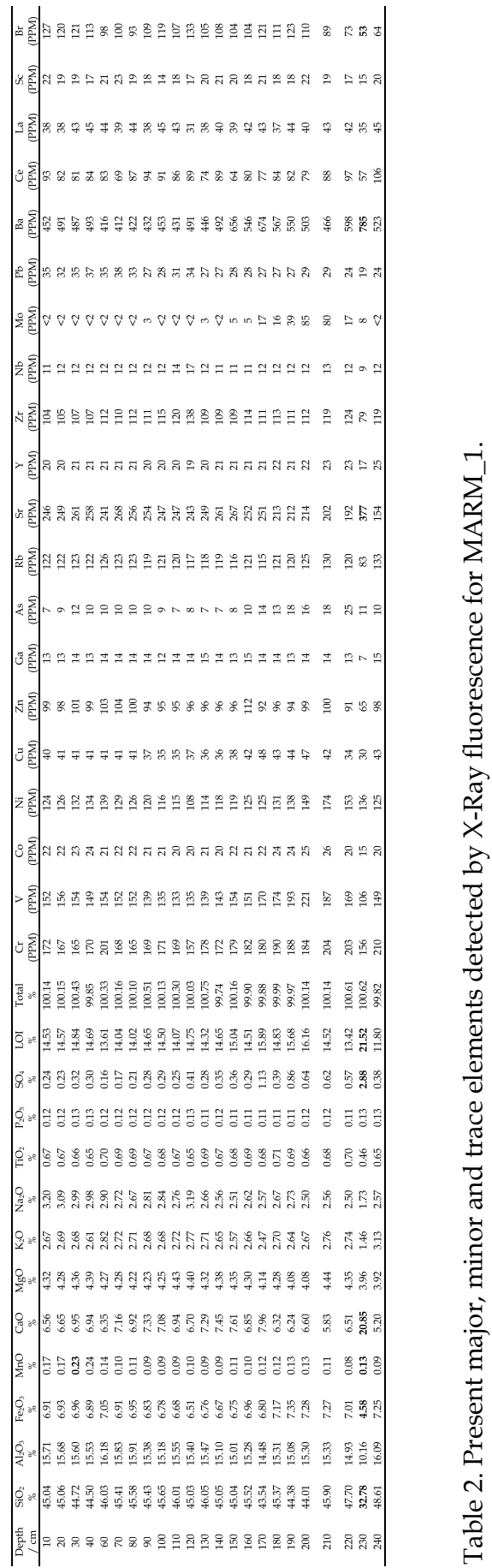




\begin{tabular}{|c|c|c|c|c|c|c|c|c|c|c|c|c|}
\hline Depth / cm & aragonite & quartz & calcite & dolomite & anorthite & albite & halite & pyrite & alpha-soufre & pyroxène & anorthoclase & orthoc \\
\hline 10 & $<5$ & $>20$ & $>20$ & $<5$ & $<5$ & $<5$ & $>5-<20$ & $<5$ & $<5$ & none & $<5$ & $<5$ \\
\hline 20 & $<5$ & $>20$ & $>20$ & $<5$ & $<5$ & $<5$ & $>5-<20$ & $<5$ & $<5$ & none & $<5$ & $<5$ \\
\hline 30 & $<5$ & $>20$ & $>5-<20$ & $>5-<20$ & $<5$ & $<5$ & $>5-<20$ & $<5$ & $<5$ & none & $<5$ & $<5$ \\
\hline 40 & $<5$ & $>20$ & $>5-<20$ & $>5-<20$ & $<5$ & $<5$ & $>5-<20$ & $<5$ & $<5$ & none & $<5$ & $<5$ \\
\hline 60 & $<5$ & $>20$ & $>20$ & $<5$ & $<5$ & $<5$ & $<5$ & $<5$ & $<5$ & none & $<5$ & $<5$ \\
\hline 70 & $<5$ & $>20$ & $>20$ & $<5$ & $<5$ & $<5$ & $<5$ & $<5$ & $<5$ & none & $<5$ & $<5$ \\
\hline 80 & $<5$ & $>20$ & $>20$ & $<5$ & $<5$ & $<5$ & $<5$ & $<5$ & $<5$ & none & $<5$ & $<5$ \\
\hline 90 & $<5$ & $>20$ & $>20$ & $<5$ & $<5$ & $<5$ & $<5$ & $<5$ & $<5$ & none & $<5$ & $<5$ \\
\hline 100 & $<5$ & $>20$ & $>20$ & $<5$ & $<5$ & $<5$ & $<5$ & $<5$ & $<5$ & none & $<5$ & $<5$ \\
\hline 110 & $<5$ & $>20$ & $>20$ & $<5$ & $<5$ & $<5$ & $<5$ & $<5$ & $<5$ & none & $<5$ & $<5$ \\
\hline 120 & $<6$ & $>20$ & $>20$ & $<5$ & $<5$ & $<5$ & $<5$ & $<5$ & $<5$ & none & $<5$ & $<5$ \\
\hline 130 & $<5$ & $>20$ & $>20$ & $<5$ & $<5$ & $<5$ & $<5$ & $<5$ & $<5$ & none & $<5$ & $<5$ \\
\hline 140 & $<5$ & $>20$ & $>20$ & $<5$ & $<5$ & $<5$ & $<5$ & $<5$ & $<5$ & none & $<5$ & $<$ \\
\hline 150 & $<5$ & $>20$ & $>20$ & $<5$ & $<5$ & $<5$ & $<5$ & $<5$ & $<5$ & none & $<5$ & $<5$ \\
\hline 160 & $<5$ & $>20$ & $>20$ & $<5$ & $<5$ & $<5$ & $<5$ & $<5$ & $<5$ & none & $<5$ & $<$ \\
\hline 170 & $<5$ & $>20$ & $>5-<20$ & $<5$ & $>5-<20$ & $>5-<20$ & $<5$ & $<5$ & $<5$ & none & $<5$ & $<5$ \\
\hline 180 & $<5$ & $>20$ & $>5-<20$ & $<5$ & $>5-<20$ & $>5-<20$ & $<5$ & $<5$ & $<5$ & none & $<5$ & \\
\hline 190 & $<5$ & $>20$ & $>5-<20$ & $<5$ & $>5-<20$ & $>5-<20$ & $<5$ & $<5$ & $<5$ & none & $<5$ & \\
\hline 200 & $<5$ & $>20$ & $>5-<20$ & $<5$ & $>5-<20$ & $>5-<20$ & $<5$ & $<5$ & $<5$ & none & $<5$ & \\
\hline 210 & $<5$ & $>20$ & $>5-<20$ & $<5$ & $>5-<20$ & $>5-<20$ & $<5$ & $<5$ & $<5$ & none & $<5$ & \\
\hline 220 & $<5$ & $>20$ & $>5-<20$ & $<5$ & $>5-<20$ & $>5-<20$ & $<5$ & $<5$ & $<5$ & none & $<5$ & \\
\hline 230 & $<5$ & $>5-<20$ & $>20$ & $<5$ & $<5$ & $<5$ & $<5$ & $<5$ & $<5$ & none & $<5$ & $<5$ \\
\hline 240 & $<5$ & $>20$ & $>5-<20$ & $<5$ & $>5-<20$ & $>5-<20$ & $<5$ & $<5$ & $<5$ & none & $<5$ & $<$ \\
\hline
\end{tabular}

Table 3. Identification and semi-quantitative evaluation of the various mineral phases present in sed 


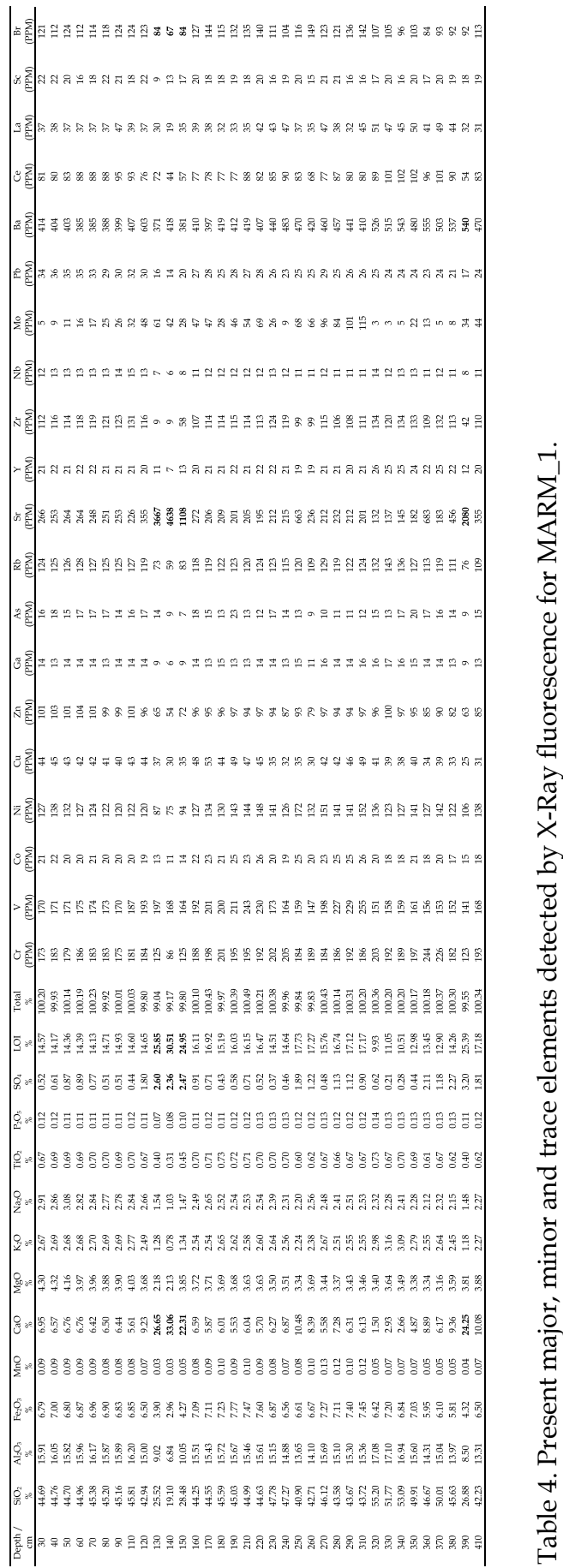




\begin{tabular}{|c|c|c|c|c|c|c|c|c|c|c|c|c|}
\hline Depth / cm & aragonite & quartz & calcite & dolomite & anorthite & albite & halite & pyrite & $\begin{array}{l}\text { alpha- } \\
\text { soufre }\end{array}$ & pyroxène & anorthoclase & orthc \\
\hline 30 & $<5$ & $>20$ & $>20$ & $<5$ & $<5$ & $>5-<20$ & $>5-<20$ & $<5$ & none & $<5$ & none & \\
\hline 40 & $<5$ & $>20$ & $>20$ & $<5$ & $<5$ & $>5-<20$ & $>5-<20$ & $<5$ & none & $<5$ & none & $\mathrm{nc}$ \\
\hline 50 & $<5$ & $>20$ & $>20$ & $<5$ & $<5$ & $>5-<20$ & $>5-<20$ & $<5$ & none & $<5$ & none & \\
\hline 60 & $<5$ & $>20$ & $>20$ & $<5$ & $<5$ & $>5-<20$ & $>5-<20$ & $<5$ & none & $<5$ & none & \\
\hline 70 & $<5$ & $>20$ & $>20$ & $<5$ & $<5$ & $>5-<20$ & $>5-<20$ & $<5$ & none & $<5$ & none & \\
\hline 80 & $<5$ & $>20$ & $>20$ & $<5$ & $<5$ & $>5-<20$ & $>5-<20$ & $<5$ & none & $<5$ & none & \\
\hline 90 & $<5$ & $>20$ & $>20$ & $<5$ & $<5$ & $>5-<20$ & $>5-<20$ & $<5$ & none & $<5$ & none & \\
\hline 110 & $<5$ & $>20$ & $>20$ & $<5$ & $<5$ & $>5-<20$ & $>5-<20$ & $<5$ & none & $<5$ & none & \\
\hline 120 & $>5-<20$ & $>20$ & $>20$ & $<5$ & $<5$ & $>5-<20$ & $>5-<20$ & $<5$ & none & $<5$ & none & \\
\hline 130 & $>20$ & $>5-<20$ & $>5-<20$ & $<5$ & $<5$ & $<5$ & $>5-<20$ & $<5$ & $<5$ & $<5$ & none & \\
\hline 140 & $>20$ & $>5-<20$ & $>5-<20$ & $<5$ & $<5$ & $<5$ & $<5$ & $<5$ & none & $<5$ & none & \\
\hline 150 & $>5-<20$ & $>20$ & $>5-<20$ & $<5$ & $<5$ & $<5$ & $<5$ & $<5$ & none & $>5-<20$ & none & \\
\hline 160 & $<5$ & $>20$ & $>5-<20$ & $<5$ & $<5$ & $>5-<20$ & $>5-<20$ & $<5$ & none & $<5$ & none & \\
\hline 170 & $<5$ & $>20$ & $>5-<20$ & $<5$ & $<5$ & $>5-<20$ & $>5-<20$ & $<5$ & none & $<5$ & none & \\
\hline 180 & $<5$ & $>20$ & $>5-<20$ & $<5$ & $<5$ & $>5-<20$ & $>5-<20$ & $>5-<20$ & none & $<5$ & none & \\
\hline 190 & $<5$ & $>20$ & $>5-<20$ & $<5$ & $<5$ & $>5-<20$ & $>5-<20$ & $>5-<20$ & none & $<5$ & none & \\
\hline 210 & $<5$ & $>20$ & $>5-<20$ & $<5$ & $<5$ & $>5-<20$ & $>5-<20$ & $>5-<20$ & none & $<5$ & none & \\
\hline 220 & $<5$ & $>20$ & $>20$ & $<5$ & $<5$ & $>5-<20$ & $>5-<20$ & $>5-<20$ & none & $<5$ & none & \\
\hline 230 & $<5$ & $>20$ & $>20$ & $<5$ & $<5$ & $>5-<20$ & $>5-<20$ & $>5-<20$ & none & $<5$ & none & \\
\hline 240 & $<5$ & $>20$ & $>20$ & $<5$ & $<5$ & $>5-<20$ & $>5-<20$ & $>5-<20$ & none & $<5$ & none & \\
\hline 250 & $<5$ & $>20$ & $>20$ & $<5$ & $<5$ & $>5-<20$ & $>5-<20$ & $>5-<20$ & none & $<5$ & none & \\
\hline 260 & $<5$ & $>20$ & $>5-<20$ & $<5$ & $<5$ & $<5$ & $>5-<20$ & $<5$ & none & $>5-<20$ & none & \\
\hline 270 & $<5$ & $>20$ & $>20$ & $<5$ & $<5$ & $>5-<20$ & $>5-<20$ & $>5-<20$ & none & $<5$ & none & \\
\hline 280 & none & $>20$ & $>20$ & $<5$ & $<5$ & $>5-<20$ & $>5-<20$ & $>5-<20$ & none & $<5$ & none & \\
\hline 290 & $<5$ & $>20$ & $>20$ & $<5$ & $<5$ & $>5-<20$ & $>5-<20$ & $>5-<20$ & none & $<5$ & none & \\
\hline 310 & $<5$ & $>20$ & $>20$ & $<5$ & $<5$ & $>5-<20$ & $>5-<20$ & $>5-<20$ & none & $<5$ & none & \\
\hline 320 & none & $>5-<20$ & $<5$ & $<5$ & $>5-<20$ & $>20$ & $<5$ & $<5$ & none & $<5$ & $>5-<20$ & \\
\hline 330 & none & $>20$ & $>20$ & $<5$ & $<5$ & $>5-<20$ & $>5-<20$ & $>5-<20$ & none & $<5$ & none & \\
\hline 340 & none & $>20$ & $>20$ & $<5$ & $<5$ & $>5-<20$ & $>5-<20$ & $>5-<20$ & none & $<5$ & none & \\
\hline 350 & none & $>20$ & $>20$ & $<5$ & $<5$ & $>5-<20$ & $>5-<20$ & $>5-<20$ & none & $<5$ & none & \\
\hline 360 & $>5-<20$ & $>20$ & $<5$ & $<5$ & $<5$ & $<5$ & $<5$ & $<5$ & none & $>5-<20$ & none & \\
\hline 370 & none & $>20$ & $>20$ & $<5$ & $<5$ & $>5-<20$ & $>5-<20$ & $>5-<20$ & none & $<5$ & none & \\
\hline 380 & $<5$ & $>20$ & $>5-<20$ & $<5$ & $<5$ & $<5$ & $>5-<20$ & $<5$ & none & $>5-<20$ & none & \\
\hline 390 & $>5-<20$ & $>20$ & $>5-<20$ & $<5$ & $<5$ & $<5$ & $<5$ & $<5$ & none & $>5-<20$ & none & \\
\hline 410 & none & $>20$ & $>5-<20$ & $<5$ & $<5$ & $<5$ & $>5-<20$ & $<5$ & none & $>5-<20$ & none & no \\
\hline
\end{tabular}

Table 5. Identification and semi-quantitative evaluation of the various mineral phases present in sed 


\section{Conclusion}

Natural-gas hydrate systems have been studied for decades from both fundamental and industrial interests. The fundamental researches were stimulated by those who want to advance knowledge in the carbon cycling of the ocean, the importance of hydrates for living methanogen-communities or its role in marine slope failure and climate change. Beside, because for a long time it has been considered as a geohazard for the petroleum industry, the applied researches were chiefly orientated to considering natural-gas hydrate systems as a geological structure which needs to be localized, described and taken in consideration into their seafloor-installation optimisation software. Now the game is changing and the major industrial impetuses come from future applications to methane production and/ or carbondioxide sequestration. However, whatever the issue to deal with, it is essential to use a versatile approach combining field data, lab experiments and modelling if we want to achieve a high level of understanding of the system. It is only after completing this work that we will be able to provide reliable prediction on the evolution of a natural-gas hydrate system upon either heating by hot reservoir fluid flowing through a pipeline, large-scale $\mathrm{CO}_{2}$ injection or large-volume methane extraction by natural or anthropogenic perturbation.

In this chapter, we intended to concisely present the geochemical formalism relevant to the study of natural-gas hydrate systems, and its contribution to the overall understanding of such systems. Based on the Western High example in the sea of Marmara, we have proposed a geochemical description of the dynamics of a hydrate accumulation zone by constraining as far as we can the origins of both the hydrate-forming gases and the associated pore-fluid. Therefore, three intimately related materials have been used in this approach: 1) the hydrate samples, especially the gases which are bound into the hydrates and which seeps to the seafloor, 2) the pore fluid which consists of the hydrate-coexisting phase and the source of the hydrate-water, 3) the sediment which is the geological matrix in which the hydrates are formed and interacts.

At the end of our study, the following conclusions have been drawn:

- The natural gas feeding the NGHOZ is of thermogenic origin and has undergone methanogenesis following biodegradation in subsurface. This natural gas certainly shares the same source rock than the predominantly-thermogenic gas fields of the Thrace basin. However, up to now there are no discovered gas fields meeting the methanogenesis following biodegradation requirements in the Thrace basin.

- The gas, especially the methane, is not only involved in the hydrate formation, but also in the associated AOM process. In fact, part of the methane reacts with the dissolved sulphate above the hydrate accumulation zone. This reaction releases carbonate ions which leads to the precipitation of authigenic carbonates under saturation of the pore fluid. The resulting pore-fluid and sediment profiles reflect the spatial heterogeneity of this geochemical process.

- The X-ray CT scan analysis of the core segments in combination with the XRF and the XRD analyses of targeted sediment samples enabled us to evaluate the spatial distribution of bivalves and carbonate concretions. The results show that bivalves are buried in the upper part of the sediment where the gas bubbles have been sampled. A high concentration of carbonate concretions is also found at the same site but distributed below.

Finally, this example enables us to better appreciate the geochemical contribution in the overall understanding of the natural-gas hydrate system. However, it is important to keep in 
mind that each natural-gas hydrate system is unique, and only a multidisciplinary investigation combined with a multi-analyses approach can lead to a reliable interpretation.

\section{Acknowledgment}

The authors acknowledge the crews of both MARMARA2010 cruises as well as the PSO for ICP-MS analyses and the hospital "La Cavale Blanche" for the X-ray scan analyses. Sylvain BERMELL, Mickael ROVERE, Angélique ROUBI, Gilbert FLOCH, Pr. Marie-Madeleine BLANC-VALLERON are gratefully acknowledged for their contributions.

\section{References}

Aksu, A., Hiscott, R., Kaminski, M., Mudie, P., Gillespie, H., Abrajano, T. and Yaar, D., 2002. Last glacial-Holocene paleoceanography of the Black Sea and Marmara Sea: stable isotopic, foraminiferal and coccolith evidence. Marine Geology, 190(1-2): 119-149.

Barka, A., Akyuz, H., Altunel, E., Sunal, G., Cakir, Z., Dikbas, A., Yerli, B., Armijo, R., Meyer, B. and De Chabalier, J., 2002. The surface rupture and slip distribution of the 17 August 1999 Izmit earthquake (M 7.4), North Anatolian fault. Bulletin of the Seismological Society of America, 92(1): 43.

Bayhan, E., Ergin, M., Temel, A. and Keskin, S., 2001. Sedimentology and mineralogy of surficial bottom deposits from the Aegean-Canakkale-Marmara transition (Eastern Mediterranean): effects of marine and terrestrial factors. Marine Geology, 175(1-4): 297-315.

Bernard, B.B., Brooks, J.M. and Sackett, W.M., 1978. Light-hydrocarbons in recent texas continental-shelf and slope sediments. Journal of Geophysical Research-Oceans and Atmospheres, 83(NC8): 4053-4061.

Berner, R., 1980. Early diagenesis: A theoretical approach. Princeton Univ Pr.

Berner, U. and Faber, E., 1996. Empirical carbon isotope/maturity relationships for gases from algal kerogens and terrigenous organic matter, based on dry, open-system pyrolysis. Organic Geochemistry, 24(10-11): 947-955.

Bhatnagar, G., Chapman, W.G., Dickens, G.R., Dugan, B. and Hirasaki, G.J., 2008. Sulfatemethane transition as a proxy for average methane hydrate saturation in marine sediments. Geophysical Research Letters, 35(3).

Bhatnagar, G., Chatterjee, S., Chapman, W.G., Dugan, B., Dickens, G.R. and Hirasaki, G.J., 2011. Analytical theory relating the depth of the sulfate-methane transition to gas hydrate distribution and saturation. Geochemistry Geophysics Geosystems, 12.

Boetius, A., Ravenschlag, K., Schubert, C.J., Rickert, D., Widdel, F., Gieseke, A., Amann, R., Jorgensen, B.B., Witte, U. and Pfannkuche, O., 2000. A marine microbial consortium apparently mediating anaerobic oxidation of methane. Nature, 407(6804): 623-626.

Borowski, W.S., Paull, C.K. and Ussler, W., 1996. Marine pore-water sulfate profiles indicate in situ methane flux from underlying gas hydrate. Geology, 24(7): 655-658.

Borowski, W.S., Paull, C.K. and Ussler, W., 1999. Global and local variations of interstitial sulfate gradients in deep-water, continental margin sediments: Sensitivity to underlying methane and gas hydrates. Marine Geology, 159(1-4): 131-154.

Boudreau, B., 1997. Diagenetic Models and their Implementation, 414 pp. Springer-Verlag, Berlin.

Bourry, C., Chazallon, B., Charlou, J.L., Donval, J.P., Ruffine, L., Henry, P., Geli, L., Cagatay, M.N., Inan, S. and Moreau, M., 2009. Free gas and gas hydrates from the Sea of 
Marmara, Turkey Chemical and structural characterization. Chemical Geology, 264(1-4): 197-206.

Cagatay, M.N., Gorur, N., Algan, O., Eastoe, C., Tchapalyga, A., Ongan, D., Kuhn, T. and Kuscu, I., 2000. Late Glacial-Holocene palaeoceanography of the Sea of Marmara: timing of connections with the Mediterranean and the Black Seas. Marine Geology, 167(3-4): 191-206.

Calvert, S. and Pedersen, T., 1993. Geochemistry of recent oxic and anoxic marine sediments: Implications for the geological record. Marine Geology, 113(1-2): 67-88.

Charlou, J., Donval, J., Fouquet, Y., Ondreas, H., Knoery, J., Cochonat, P., Levache, D., Poirier, Y., Jean-Baptiste, P. and Fourre, E., 2004. Physical and chemical characterization of gas hydrates and associated methane plumes in the CongoAngola Basin. Chemical Geology, 205(3-4): 405-425.

Chung, H., Gormly, J. and Squires, R., 1988. Origin of gaseous hydrocarbons in subsurface environments: theoretical considerations of carbon isotope distribution. Chemical Geology, 71(1-3): 97-104.

Collett, T., Johnson, A., Knapp, C. and Boswell, R., 2010. natural gas hydrates energy resource potential and associated geologic hazards. AAPG Memoir 89.

Coskun, B., 1997. Oil and gas fields - transfer zone relationships, Thrace basin, NW Turkey. Marine and Petroleum Geology, 14(4): 401-416.

Coskun, B., 2000. North Anatolian Fault-Saros Gulf relationships and their relevance to hydrocarbon exploration, northern Aegean Sea, Turkey. Marine and Petroleum Geology, 17(6): 751-772.

Dimitrakopoulos, R. and Muehlenbachs, K., 1987. Biodegradation of petroleum as a source of $13 \mathrm{C}$-enriched carbon dioxide in the formation of carbonate cement. Chemical Geology, 65(3-4): 283-291.

El Maghraoui, M., Joron, J.L., Etoubleau, J., Cambon, P. and Treuil, M., 1998. Determination of forty major and trace elements in GPMA magmatic rock reference materials using X-ray fluorescence spectrometry (XRF) and instrumental neutron activation analysis (INAA). Geostandards Newsletter, 23(1): 59 - 68.

Etiope, G., Feyzullayev, A. and Baciu, C., 2009a. Terrestrial methane seeps and mud volcanoes: A global perspective of gas origin. Marine and Petroleum Geology, 26(3): 333-344.

Etiope, G., Feyzullayev, A., Milkov, A.V., Waseda, A., Mizobe, K. and Sun, C.H., 2009 b. Evidence of subsurface anaerobic biodegradation of hydrocarbons and potential secondary methanogenesis in terrestrial mud volcanoes. Marine and Petroleum Geology, 26(9): 1692-1703.

Gasperini, L., Polonia, A., Bortoluzzi, G., Henry, P., Le Pichon, X., Tryon, M., Cagatay, N. and Geli, L., 2011. How far did the surface rupture of the 1999 Izmit earthquake reach in Sea of Marmara? Tectonics, 30.

Gürgey, K., 2009. Geochemical overview and undiscovered gas resources generated from Hamitabat petroleum system in the Thrace Basin, Turkey. Marine and Petroleum Geology, 26(7): 1240-1254.

Gürgey, K., Philp, R., Clayton, C., Emiro lu, H. and Siyako, M., 2005. Geochemical and isotopic approach to maturity/source/mixing estimations for natural gas and associated condensates in the Thrace Basin, NW Turkey. Applied Geochemistry, 20(11): 2017-2037. 
Head, I., Jones, D. and Larter, S., 2003. Biological activity in the deep subsurface and the origin of heavy oil. Nature, 426(6964): 344-352.

Henriet, J.P. and Mienert, J., 1998. Gas hydrates: relevance to world margin stability and climate change. Geological Society Pub House.

Hensen, C., Zabel, M., Pfeifer, K., Schwenk, T., Kasten, S., Riedinger, N., Schulz, H.D. and Boettius, A., 2003. Control of sulfate pore-water profiles by sedimentary events and the significance of anaerobic oxidation of methane for the burial of sulfur in marine sediments. Geochimica et Cosmochimica Acta, 67(14): 2631-2647.

Hoşgörmez, H. and Yalçin, M., 2005. Gas-source rock correlation in Thrace basin, Turkey. Marine and Petroleum Geology, 22(8): 901-916.

Hoşgörmez, H., Yalçin, M., Cramer, B., Gerling, P. and Mann, U., 2005. Molecular and isotopic composition of gas occurrences in the Thrace basin (Turkey): origin of the gases and characteristics of possible source rocks. Chemical Geology, 214(1-2): 179-191.

Jones, D., Head, I., Gray, N., Adams, J., Rowan, A., Aitken, C., Bennett, B., Huang, H., Brown, A. and Bowler, B., 2007. Crude-oil biodegradation via methanogenesis in subsurface petroleum reservoirs. Nature, 451(7175): 176-180.

Joye, S.B., Boetius, A., Orcutt, B.N., Montoya, J.P., Schulz, H.N., Erickson, M.J. and Lugo, S.K., 2004. The anaerobic oxidation of methane and sulfate reduction in sediments from Gulf of Mexico cold seeps. Chemical Geology, 205(3-4): 219-238.

Karaca, D., Hensen, C. and Wallmann, K., 2010. Controls on authigenic carbonate precipitation at cold seeps along the convergent margin off Costa Rica. Geochemistry Geophysics Geosystems, 11: 19.

Kastner, M., Claypool, G. and Robertson, G., 2008. Geochemical constraints on the origin of the pore fluids and gas hydrate distribution at Atwater Valley and Keathley Canyon, northern Gulf of Mexico. Marine and Petroleum Geology, 25(9): 860-872.

Krey, V., Canadell, J.G., Nakicenovic, N., Abe, Y., Andruleit, H., Archer, D., Grubler, A., Hamilton, N.T.M., Johnson, A., Kostov, V., Lamarque, J.-F., Langhorne, N., Nisbet, E.G., O'Neill, B., Riahi, K., Riedel, M., Wang, W. and Yakushev, V., 2009. Gas hydrates: entrance to a methane age or climate threat? Environmental Research Letters, 4(3).

Kvenvolden, K., 1999. Potential effects of gas hydrate on human welfare. National Acad Sciences, pp. 3420-3426.

Kvenvolden, K.A., 1988. Methane hydrate - A major reservoir of carbon in the shallow geosphere. Chemical Geology, 71(1-3): 41-51.

Kvenvolden, K.A., 2000. Gas hydrate and humans. Annals of the New York Academy of Sciences, 912(1): 17-22.

Le Pichon, X., Sengor, A.M.C., Demirbag, E., Rangin, C., Imren, C., Armijo, R., Gorur, N., Cagatay, N., de Lepinay, B.M., Meyer, B., Saatcilar, R. and Tok, B., 2001. The active Main Marmara Fault. Earth and Planetary Science Letters, 192(4): 595-616.

Luff, R. and Wallmann, K., 2003. Fluid flow, methane fluxes, carbonate precipitation and biogeochemical turnover in gas hydrate-bearing sediments at Hydrate Ridge, Cascadia Margin: Numerical modeling and mass balances. Geochimica et Cosmochimica Acta, 67(18): 3403-3421.

Martens, C.S. and Val Klump, J., 1984. Biogeochemical cycling in an organic-rich coastal marine basin 4 . An organic carbon budget for sediments dominated by sulfate reduction and methanogenesis. Geochimica et Cosmochimica Acta, 48(10): 1987-2004. 
Maslin, M., Owen, M., Betts, R., Day, S., Dunkley Jones, T. and Ridgwell, A., 2010. Gas hydrates: past and future geohazard? Philosophical Transactions of the Royal Society a-Mathematical Physical and Engineering Sciences, 368(1919): 2369-2393.

Max, M., 2003. Natural gas hydrate: in oceanic and permafrost environments. Kluwer Academic Pub.

McHugh, C.M.G., Gurung, D., Giosan, L., Ryan, W.B.F., Mart, Y., Sancar, U., Burckle, L. and Cagatay, M.N., 2008. The last reconnection of the Marmara Sea (Turkey) to the World Ocean: A paleoceanographic and paleoclimatic perspective. Marine Geology, 255(1-2): 64-82.

Okay, A.I., Demirbag, E., Kurt, H., Okay, N. and Kuscu, I., 1999. An active, deep marine strikeslip basin along the North Anatolian fault in Turkey. Tectonics, 18(1): 129-147.

Orcutt, B.N., Boetius, A., Lugo, S.K., MacDonald, I.R., Samarkin, V.A. and Joye, S.B., 2004. Life at the edge of methane ice: microbial cycling of carbon and sulfur in Gulf of Mexico gas hydrates. Chemical Geology, 205(3-4): 239-251.

Pallasser, R., 2000. Recognising biodegradation in gas/oil accumulations through the 13C compositions of gas components. Organic Geochemistry, 31(12): 1363-1373.

Paull, C. and Dillon, W., 2001. Natural gas hydrates: occurrence, distribution, and detection. American Geophysical Union, Washington, DC.

Plaza-Faverola, A., Westbrook, G.K., Ker, S., Exley, R.J.K., Gailler, A., Minshull, T.A. and Broto, K., 2010. Evidence from three-dimensional seismic tomography for a substantial accumulation of gas hydrate in a fluid-escape chimney in the Nyegga pockmark field, offshore Norway. Journal of Geophysical Research-Solid Earth, 115.

Pohlman, J., Canuel, E., Chapman, N., Spence, G., Whiticar, M. and Coffin, R., 2005. The origin of thermogenic gas hydrates on the northern Cascadia Margin as inferred from isotopic $(13 \mathrm{C} / 12 \mathrm{C}$ and $\mathrm{D} / \mathrm{H})$ and molecular composition of hydrate and vent gas. Organic Geochemistry, 36(5): 703-716.

Pohlman, J.W., Ruppel, C., Hutchinson, D.R., Downer, R. and Coffin, R.B., 2008. Assessing sulfate reduction and methane cycling in a high salinity pore water system in the northern Gulf of Mexico. Marine and Petroleum Geology, 25(9): 942-951.

Reagan, M.T. and Moridis, G.J., 2008. Dynamic response of oceanic hydrate deposits to ocean temperature change. Journal of Geophysical Research-Oceans, 113(C12).

Reeburgh, W.S., 1976. Methane consumption in Cariaco Trench waters and sediments. Earth and Planetary Science Letters, 28(3): 337-344.

Reichel, T. and Halbach, P., 2007. An authigenic calcite layer in the sediments of the Sea of Marmara - A geochemical marker horizon with pale oceanographic significance. Deep-Sea Research Part Ii-Topical Studies in Oceanography, 54(11-13): 1201-1215.

Richter, T.O., van der Gaast, S., Koster, B., Vaars, A., Gieles, R., de Stigter, H.C., De Haas, H. and van Weering, T.C.E., 2006. The Avaatech XRF Core Scanner: technical description and applications to NE Atlantic sediments. Geological Society, London, Special Publications, 267(1): 39-50.

Schaller, T., Christoph Moor, H. and Wehrli, B., 1997a. Sedimentary profiles of Fe, Mn, V, Cr, As and Mo as indicators of benthic redox conditions in Baldeggersee. Aquatic Sciences-Research Across Boundaries, 59(4): 345-361.

Schaller, T., Moor, H.C. and Wehrli, B., 1997b. Reconstructing the iron cycle from the horizontal distribution of metals in the sediment of Baldeggersee. Aquatic SciencesResearch Across Boundaries, 59(4): 326-344. 
Schaller, T. and Wehrli, B., 1996. Geochemical-focusing of manganese in lake sediments - an indicator of deep-water oxygen conditions. Aquatic Geochemistry, 2(4): 359-378.

Schoell, M., 1983. Genetic characterization of natural gases. Aapg Bulletin, 67(12): 2225-2238.

Schulz, H.D. and Zabel, M., 2000. Marine geochemistry. Springer.

Sen, S., YIllar, S. and Erdal Kerey, 2009. Allochthonous blocks misidentified as the basement: Implication for petroleum exploration in the SW Thrace Basin (Turkey). Journal of Petroleum Science and Engineering, 64(1-4): 55-66.

Şen Şamil , Selin Yillar and Kerey Erdal 2009. Allochthonous blocks misidentified as the basement: Implication for petroleum exploration in the SW Thrace Basin (Turkey). Journal of Petroleum Science and Engineering, 64(1-4): 55-66.

Sloan, E.D. and Koh, C.A., 2008. Clathrate hydrates of natural gases. CRC.

Sultan, N., Marsset, B., Ker, S., Marsset, T., Voisset, M., Vernant, A.M., Bayon, G., Cauquil, E., Adamy, J., Colliat, J.L. and Drapeau, D., 2010. Hydrate dissolution as a potential mechanism for pockmark formation in the Niger delta. Journal of Geophysical Research-Solid Earth, 115.

Treude, T., Boetius, A., Knittel, K., Wallmann, K. and Jorgensen, B.B., 2003. Anaerobic oxidation of methane above gas hydrates at Hydrate Ridge, NE Pacific Ocean. Marine Ecology-Progress Series, 264: 1-14.

Tryon, M.D., Henry, P., Cagatay, M.N., Zitter, T.A.C., Geli, L., Gasperini, L., Burnard, P., Bourlange, S. and Grall, C., 2010. Pore fluid chemistry of the North Anatolian Fault Zone in the Sea of Marmara: A diversity of sources and processes. Geochemistry Geophysics Geosystems, 11.

Ussler III, W., Paull, C. and Fullagar, P., 2000. 2. Pore-Water Strontium Isotopes from the Leg 171B Drilling Transect down the Blake Spur.

Utkucu, M., Nalbant, S.S., McCloskey, J., Steacy, S. and Alptekin, O., 2003. Slip distribution and stress changes associated with the 1999 November 12, Duzce (Turkey) earthquake (M (w)=7.1). Geophysical Journal International, 153(1): 229-241.

Vidal, L., Ménot, G., Joly, C., Bruneton, H., Rostek, F., Çagatay, M., Major, C.O. and Bard, E., Hydrology in the Sea of Marmara during the last $23 \mathrm{ka}$ : implications for timing of Black Sea connections and sapropel deposition.

Wallmann, K., Aloisi, G., Haeckel, M., Obzhirov, A., Pavlova, G. and Tishchenko, P., 2006. Kinetics of organic matter degradation, microbial methane generation, and gas hydrate formation in anoxic marine sediments. Geochimica et Cosmochimica Acta, 70(15): 3905-3927.

Waseda, A. and Iwano, H., 2008. Characterization of natural gases in Japan based on molecular and carbon isotope compositions. Geofluids, 8(4): 286-292.

Whiticar, M.J., 1994. Correlation of natural gases with their sources. In: Magoon, L. B.; Dow, W. G. (Eds), The petroleum System: from Sources to Trap, AAPG Memoir, vol.60: pp 261-283.

Yamamoto, A., Yamanaka, Y. and Taiika, E., 2009. Modeling of methane bubbles released from large sea-floor area: Condition required for methane emission to the atmosphere. Earth and Planetary Science Letters, 284(3-4): 590-598.

Zitter, T., Henry, P., Aloisi, G., Delaygue, G., Çagatay, M., Mercier de Lepinay, B., Al-Samir, M., Fornacciari, F., Tesmer, M. and Pekdeger, A., 2008. Cold seeps along the main Marmara fault in the Sea of Marmara (Turkey). Deep-Sea Research Part I, 55(4): 552-570. 


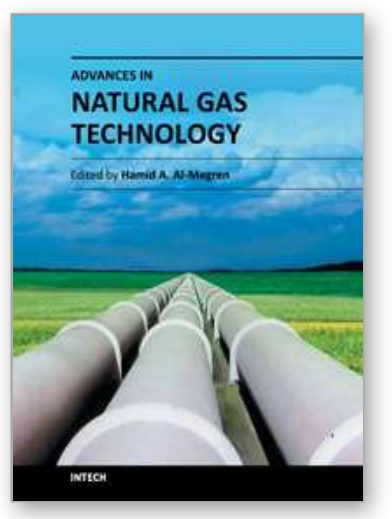

\author{
Advances in Natural Gas Technology \\ Edited by Dr. Hamid Al-Megren
}

ISBN 978-953-51-0507-7

Hard cover, 542 pages

Publisher InTech

Published online 11, April, 2012

Published in print edition April, 2012

Natural gas is a vital component of the world's supply of energy and an important source of many bulk chemicals and speciality chemicals. It is one of the cleanest, safest, and most useful of all energy sources, and helps to meet the world's rising demand for cleaner energy into the future. However, exploring, producing and bringing gas to the user or converting gas into desired chemicals is a systematical engineering project, and every step requires thorough understanding of gas and the surrounding environment. Any advances in the process link could make a step change in gas industry. There have been increasing efforts in gas industry in recent years. With state-of-the-art contributions by leading experts in the field, this book addressed the technology advances in natural gas industry.

\title{
How to reference
}

In order to correctly reference this scholarly work, feel free to copy and paste the following:

Livio Ruffine, Olivia Fandino, Joël Etoubleau, Sandrine Chéron, Jean-Pierre Donval, Yoan Germain, Emmanuel Ponzevera, Vivien Guyader, Bernard Dennielou, Giuseppe Etiope, Luca Gasperini, Bortoluzzi Giovanni, Pierre Henry, Céline Grall, Çagatay M. Namik, Charlou Jean-Luc and Géli Louis (2012). Geochemical Dynamics of the Natural-Gas Hydrate System in the Sea of Marmara, Offshore Turkey, Advances in Natural Gas Technology, Dr. Hamid Al-Megren (Ed.), ISBN: 978-953-51-0507-7, InTech, Available from: http://www.intechopen.com/books/advances-in-natural-gas-technology/geochemical-dynamicsof-the-natural-gas-hydrate-system-in-the-sea-of-marmara-offshore-turkey

\section{INTECH}

open science | open minds

\section{InTech Europe}

University Campus STeP Ri

Slavka Krautzeka 83/A

51000 Rijeka, Croatia

Phone: +385 (51) 770447

Fax: +385 (51) 686166

www.intechopen.com

\section{InTech China}

Unit 405, Office Block, Hotel Equatorial Shanghai

No.65, Yan An Road (West), Shanghai, 200040, China

中国上海市延安西路65号上海国际贵都大饭店办公楼405单元

Phone: +86-21-62489820

Fax: $+86-21-62489821$ 
(C) 2012 The Author(s). Licensee IntechOpen. This is an open access article distributed under the terms of the Creative Commons Attribution 3.0 License, which permits unrestricted use, distribution, and reproduction in any medium, provided the original work is properly cited. 